\title{
Techno-economic and behavioural analysis of battery electric, hydrogen fuel cell and hybrid vehicles in a future sustainable road transport system in the UK
}

\author{
Offer G. J. ${ }^{a}$, Contestabile M. ${ }^{b}$, Howey D. ${ }^{c}$, Clague R. ${ }^{d}$, Brandon N. P. ${ }^{a}$ \\ ${ }^{a}$ Department Earth Science Engineering, Imperial College London, SW7 2AZ, United Kingdom \\ ${ }^{b}$ Centre for Environmental Policy, Imperial College London, SW7 2AZ, United Kingdom \\ ${ }^{c}$ Department of Electrical and Electronic Engineering, Imperial College London, SW7 2AZ, United Kingdom \\ ${ }^{d}$ Energy Futures Lab, Imperial College London, SW7 2AZ, United Kingdom \\ email: gregory.offer@imperial.ac.uk, phone: +44(0)2075945018, fax: +44 (0)2075947444
}

\section{Abstract}

This paper conducts a techno-economic study on hydrogen fuel cell electric vehicles (FCV), battery electric vehicles (BEV) and hydrogen fuel cell plug-in hybrid electric vehicles (FCHEV) in the UK using cost predictions for 2030. The study includes an analysis of data on distance currently travelled by private car users daily in the UK. Results show that there may be diminishing economic returns for plug-in hybrid electric vehicles (PHEV) with battery sizes above $20 \mathrm{kWh}$, and the optimum size for a PHEV battery is between 5-15 kWh. Differences in behaviour as a function of vehicle size are demonstrated, which decreases the percentage of miles that can be economically driven using electricity for a larger vehicle. Decreasing carbon dioxide emissions from electricity generation by $80 \%$ favours larger optimum battery sizes as long as carbon is priced, and will reduce emissions considerably. However, the model does not take into account reductions in carbon dioxide emissions from hydrogen generation, assuming hydrogen will still be produced from steam reforming methane in 2030. transport

Keywords: Fuel cell vehicle; electric vehicle; hybrid vehicle; hydrogen; electricity; private

\section{Introduction}

Road transport today is responsible for a significant and growing share of global anthropogenic emissions of $\mathrm{CO}_{2}$. Moreover, it is almost entirely dependent on oil-derived fuels and therefore highly vulnerable to possible oil price shocks and supply disruptions. Finally, using oilderived fuels in internal combustion engines generates tailpipe emissions of pollutants such as $\mathrm{PM}_{10}, \mathrm{NO}_{x}$ and VOCs which are harmful to human health.

Improving road transport requires all these issues to be addressed. Managing demand and promoting co-modality ${ }^{a}$ can provide a partial solution, however introducing alternative transport fuels and vehicles is also necessary in order to achieve the objectives of decarbonisation, energy security and urban air quality.

In this paper, two of the three alternative powertrain technologies considered by the International Energy Agency (IEA) as being capable of delivering a sustainable road transport system with near-zero emissions are addressed (IEA 2008). The first is the battery electric vehicle $(\mathrm{BEV})$ and the second is the hydrogen fuel cell electric vehicle (FCV). In this study it was decided to focus exclusively on electric drive trains so the third option, biofuels, is not addressed.

Although the advantages and disadvantages of battery and hydrogen fuel cell technologies have been identified and discussed elsewhere (IEA 2004; King 2007; Bandivadekar, Bodek et al. 2008; Bandivadekar, Cheah et al. 2008; IEA 2008; King 2008; Tollefson 2008; McKinsey 2010) there is inadequate awareness of the strong synergies between them in road vehicle applications.

${ }^{a}$ Co-modality can be defined as "the efficient use of different modes [of transport] on their own and in combination" so as to obtain "an optimal and sustainable utilisation of resources". Source: European Commission (2006). Communication from the Commission to the Council and the European Parliament. Keep Europe moving - Sustainable mobility for our continent. Mid-term review of the European Commission's 2001 Transport White Paper. Brussels, 22.06.2006. EC COM(2006) 314 final. 
Despite limited analysis comparing fuel cell and combustion engine range extenders for electric vehicles (Burke 2007), BEVs and FCVs are still largely seen as mutually exclusive options. Moreover, the most recent high profile assessment of low carbon cars in the UK, the King Review (King 2007), does acknowledge that a fuel mix including hydrogen and electricity is likely, but it implicitly assumes that this will be via different vehicle platforms, and not by a single vehicle with the capability to use both electricity and hydrogen. The fuel cell plug-in hybrid (FCHEV) appears to have been mostly overlooked in the literature.

Despite studies comparing conventional, hybrid, electric and hydrogen fuel cell vehicles (Granovskii, Dincer et al. 2006; Bandivadekar, Bodek et al. 2008; Bandivadekar, Cheah et al. 2008; McKinsey 2010) there is limited literature on cost comparisons between fuel cell and fuel cell hybrids (Suppes 2005; Van Mierlo and Maggetto 2005; Suppes 2006; Burke 2007).

In response to this the authors demonstrated in a previous study (Offer, Howey et al. 2010) that a combination of electricity and hydrogen as a transport fuel could bring additional benefit to the end user in terms of both capital and running costs. A cost comparison of the lifecycle cost of BEV, FCV and FCHEV over 100,000 miles was undertaken, accounting for capital and fuel costs. A 2030 scenario was discussed and compared to a conventional gasoline-fuelled internal combustion engine (ICE) powertrain. The sensitivity analysis showed that in 2030 FCVs could achieve lifecycle cost parity with conventional gasoline vehicles, but both the BEV and FCHEV had significantly lower lifecycle costs. All vehicle platforms exhibited the most significant cost sensitivity to powertrain capital cost, followed by hydrogen cost sensitivity and the lowest sensitivity to electricity cost. The key conclusion was that the best path for future development of FCVs is the FCHEV.

The results of the previous paper were also based on the assumptions that the plug-in FCHEV had a $6 \mathrm{kWh}$ battery capacity and used electric power $50 \%$ of the time. These assumptions were somewhat arbitrary; in actual fact the optimum (minimum lifecycle cost) battery size of the vehicle is a strong function of the vehicle's specifications and driving pattern.

This paper further explores this issue by including car driving behavioural aspects in the analysis. Analysing data from the most recent UK National Travel Survey (DfT 2008) a nationwide distribution of distances currently travelled by private cars each day was generated, both aggregated for all car types and specific for main car types in turn. From this distribution, the percentage of total all-electric miles driven can be determined as a function of battery capacity; this percentage is also referred to in the literature as utility factor (Kromer and Heywood 2008; Bradley and Quinn 2010). This was then included in the model to determine how the electric only range and battery capacity affect the capital and fuel costs for different degrees of hybridisation. A combustion engine vehicle is included in the study for comparison purposes. Although we consider future efficiency improvements in combustion engine powertrains, the main focus of this paper remains the comparison between different electric powertrains based on batteries and fuel cells; hence a complete assessment of the future role of internal combustion engine powertrains also comprising plug-in hybrid architectures is beyond the scope of the present paper.

In addition, in the present paper the $\mathrm{CO}_{2}$ emissions from each option are included, and the effect that this has on the costs is discussed based upon a range of extended assumptions relative to the previous paper.

\section{Driver behaviour analysis}

In order to determine the correct sizes of the battery, the fuel cell and the hydrogen tank in a FCHEV, (i.e.: the optimum battery size assuming that the fuel cell installed power remains constant $^{b}$ ), it is necessary to consider the distribution of daily driving distances over the lifetime of the vehicle. Optimum battery size is defined as delivering the lowest lifecycle costs.

${ }^{b}$ The power of the fuel cell range extender is defined here by the power needed to propel the vehicle at constant cruising speed on a motorway, and is thus independent from the size of the battery. The fuel cell may be downsized even further to reduce costs, such that the battery is depleted at cruising speed, however, this has not been considered here. 
Assuming batteries are only recharged at night ${ }^{c}$, it is the total distance travelled in a typical day and not the length of the single trip that matters. A trip is defined as "a one-way course of travel with a single main purpose" (Anderson 2009), and several trips are possible in one day.

Both the total distance driven over the lifetime of the vehicle and the distribution of daily distances driven can be regarded as behavioural variables; the type and size of car that people purchase is also a behavioural aspect. These depend on choices that are made by the car user, who in turn is influenced by a number of factors, such as personal/ household income, the cost of motoring relative to other transport modes, the relative convenience of the various available transport modes, just to name a few.

Trends in personal transport by car have been observed in the last few decades, and they illustrate both the important role that the car plays in personal mobility in the UK, and how usage patterns can change over time. Between 1980 and the early 1990s the average miles travelled per person per year by all modes of transport in the UK grew roughly in line with GDP. Since then, however, some decoupling has been observed and the growth of average miles travelled has been slowing down (DfT 2005). Since 2005 the average distance travelled per person per year remained roughly constant, but the fraction of the distance travelled by car has kept increasing. In 2008, trips by car accounted for $63 \%$ of all trips made and almost $80 \%$ of distance travelled (DfT 2009).

Since 1980 the number of cars per household in the UK has been steadily growing, with the fraction of households having access to one or more cars going from $59 \%$ in 1980 to $74 \%$ in 2002 . As a result, during the 1990s the annual distance travelled by car drivers rose by $15 \%$, while the distance travelled by passengers remained roughly constant (DfT 2005), therefore car occupancy rates have fallen. Since around 2000, there have been more households with at least two cars than households with no car. However since 2005 car availability per household has reached a plateau (DfT 2009). During the 1990s, as result of increased car use, the average annual distance walked fell by $20 \%$ and the distance travelled by bus fell by $11 \%$; in general a shift away from public transport and towards car transport is evident, and this is also related to the fact that between 1980 and 2003 bus and rail fares have risen in real terms by over a third, while the cost of motoring has remained at or below its 1980 level (DfT 2005).

Therefore, the car in 2010 is the prevalent mode of transport for short to medium length trips in the UK, with rail and plane only taking up a significant fraction of trips longer than 350 miles; as shown in figure 1. It is also interesting to note that travel varies considerably with car availability. On average in 2008, members of car owning households made $41 \%$ more trips than people living in non-car owning households, and travelled over two and a half times as far per year (DfT 2009). Car access and income are closely related. Hence both the average number of trips and the distance travelled per person per year are strongly influenced by income level, as shown in figure 2 .

\footnotetext{
${ }^{\mathrm{c}}$ This is a conservative assumption justified by the fact that fast-charging poses significant technical and infrastructural challenges, whereas fully recharging a vehicle battery using domestic power sockets (230 $\mathrm{V} \mathrm{AC}, 13 \mathrm{~A}$ ) typically requires several hours and therefore is likely to occur overnight.
} 
This is a pre-print version of: Offer, G.J., et al., Techno-economic and behavioural analysis of battery electric, hydrogen fuel cell and hybrid vehicles in a future sustainable road transport system in the UK. Energy Policy (2011), doi:10.1016/j.enpol.2011.01.006

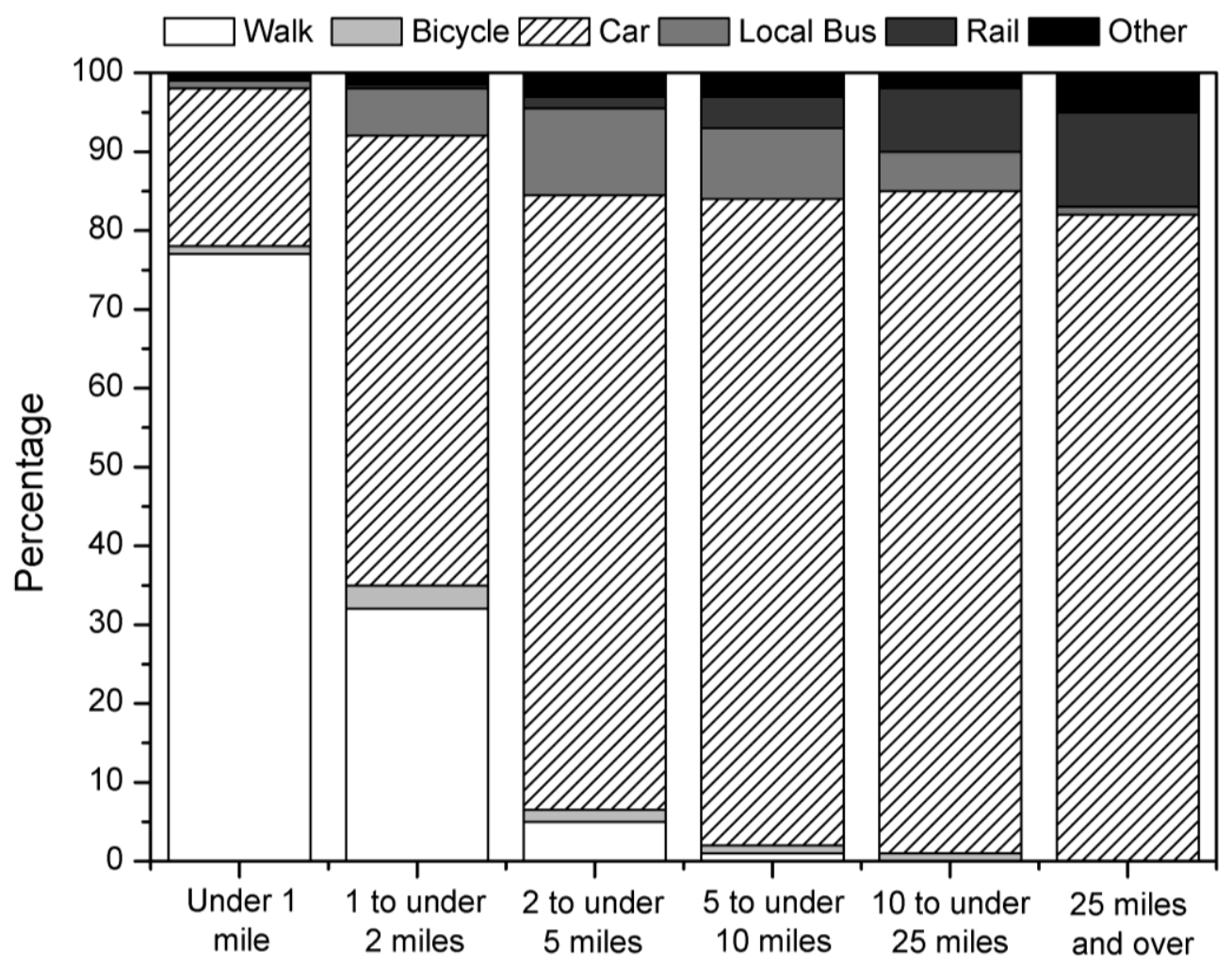

Figure 1. UK trips by main mode and length in 2008 (Adapted from: (DfT 2009))

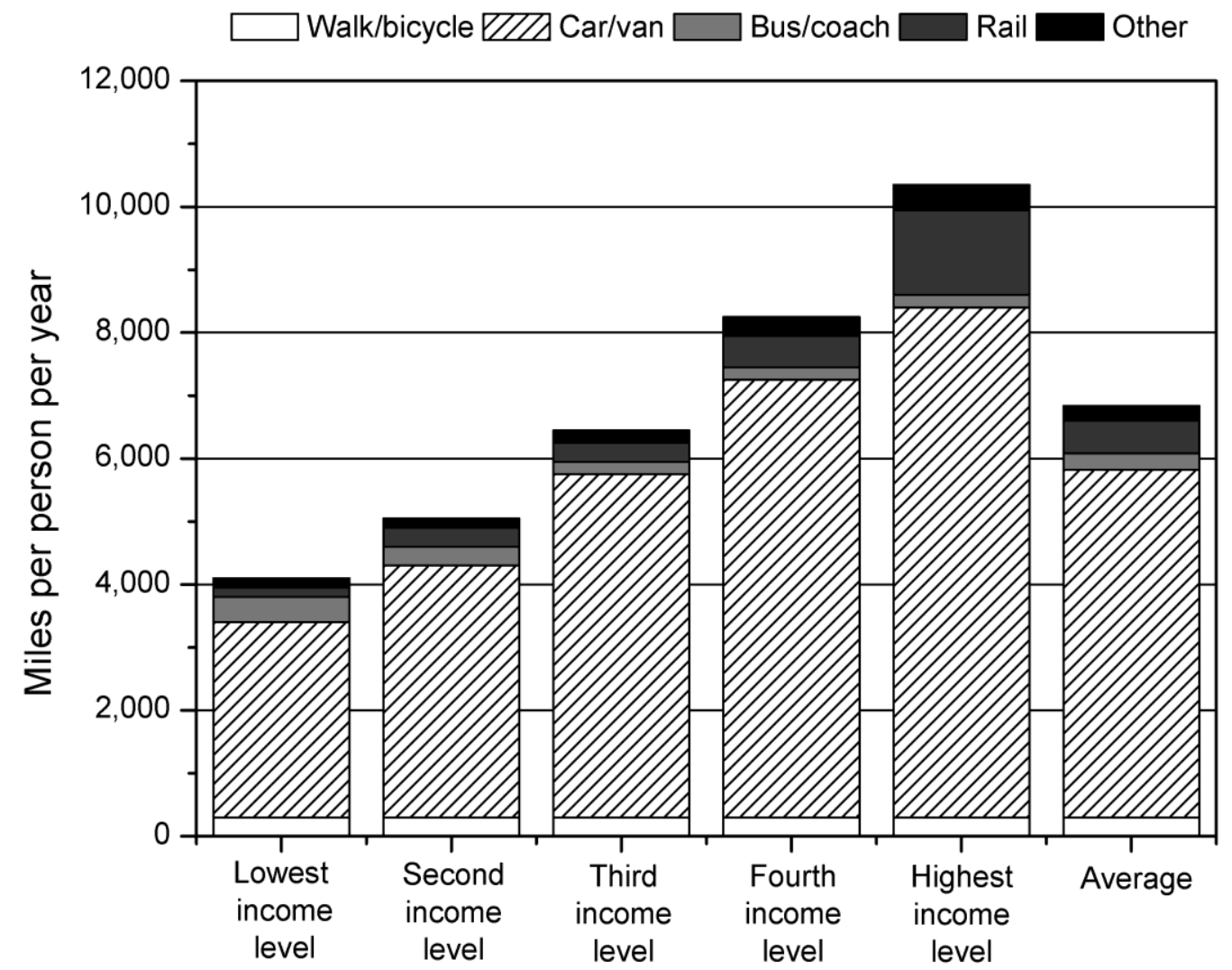

Figure 2. Average distance travelled by mode and household income in 2008 (Adapted from: (DfT 2009)) 
This is a pre-print version of: Offer, G.J., et al., Techno-economic and behavioural analysis of battery electric, hydrogen fuel cell and hybrid vehicles in a future sustainable road transport system in the UK. Energy Policy (2011), doi:10.1016/j.enpol.2011.01.006

In light of these trends, it is clear that car travel patterns do change significantly over time, and even within the same household; in fact changes in income level and car availability of an individual are bound to change his or her travel behaviour. Patterns also change as a result of policy. If the domestic transport system is to become more sustainable, the current trend towards an increasingly dominant role of the car in private transport needs to be countered by efforts aimed at promoting co-modality and managing demand for private cars. A number of policies are currently either in place or being discussed which will alter private car user behaviour, for example road user charging. Fuel and car taxation will influence both car choice and use. Moreover, there are policies that are not originally aimed at transport which however can have a strong impact on travel patterns, such as land use policies; for example, measures that favour large suburban shopping malls at the expense of high-street shops have the side effect of increasing private car use (Gross 2009).

The picture that emerges is complex. Evidence regarding the effects of policies aimed at altering travel choices is often incomplete, and unintended interactions as well as rebound effects are possible (Gross 2009). This makes it very difficult to predict exactly how demand-management policies will change behaviour and how long it may take to change current trends.

When considering behavioural change it is simplest to make one of two assumptions. Either to start with the premise that a specific technology is the optimum, such as battery electric vehicles, and then assert that behaviour must change to accommodate the technology. Or, to start with the premise that a type of behaviour is inevitable or desirable and then make technology selections that can deliver that behaviour. Often these assumptions are not made clear, and it is even possible that sometimes authors are not even aware they are making them. However, either assumption is dangerous to assert without evidence. It is not within the scope of this paper to explore these assumptions, therefore it has been assumed that behaviour will not change significantly between 2010 and 2030 in order to reduce the number of variables. This means that technologies are compared independent of behavioural change. Given the relatively slow rates of change of usage patterns over the past 2 decades and the strong preference for cars, it is suggested that this is a reasonable assumption for a forward-looking study. The sensitivity of the result to behavioural change will be explored in further papers.

For the purposes of the research, data on distance travelled by private car users daily and the distribution of travel distances have been extracted from the National Travel Survey (NTS) 2002-2006 data set (Department for Transport 2008). The NTS is a continuous household survey of the Department for Transport (DfT) that began in July 1988 and is designed to provide a databank of personal travel information for Great Britain. A large sample of UK households, representative of the national population, is surveyed every year and a wide amount of data on personal mobility is collected, including data on private car travel behaviour. NTS data is collected via two main sources. Firstly, face-to-face interviews are carried out to collect information on the household, all individual members within the household and all vehicles to which they have access. Each household member is then asked to record details of all their trips over a seven day period in a travel diary, allowing travel patterns to be linked with individual characteristics (Anderson 2009).

Here follows a brief description of the data that were extracted from the NTS and the processing methodology. Firstly the NTS dataset and all related documentation were downloaded from the UK Data Archive website. Then the following operations were carried out using the SPSS Statistics 17.0 software package:

The data file "journey" was opened; this dataset contains information on all journeys within the UK carried out by the population samples selected over the years 2002 to 2006. Despite the sample size being sufficient to allow analysis at the single year level, all 5 years of data were used in the current study, both to have a large sample size and to average the results over a longer period of time, thus maximising the stability of data.

- All journeys involving means of transport other than private cars were filtered out.

- In order to determine the distance travelled every day by private car by the population sample, the distance travelled by each individual every day was aggregated. In the data set only individual journeys are present, however adding them up and banding them produced a distribution of average daily distances driven which is shown in figure 3. 
- This distribution allows direct determination of the optimum battery size for a generic FCHEV used by the average UK driver. However, in reality various types and sizes of cars exist on the market, which are possibly used differently by their owners.

- In order to characterise the different usage patterns of different car types, the filtered and aggregated "journey" data set was merged with the corresponding cases of the "vehicle" data file. Firstly the "vehicle" data file was filtered, in order to remove all partly co-operating households ${ }^{d}$ (for consistency with the "journey" data file, where only fully co-operating households were present) and all vehicles other than cars; then, all cases where cars have no main user or where an individual is the main user of more than one car were also removed. The two data files were merged, using the "vehicle" data file as keyed table ${ }^{\mathrm{e}}$. This allowed matching each individual travelling by private car with a specific vehicle for which size and vehicle excise duty band are given.

- A distribution of average daily distances driven for different car types was arrived at, which is also represented in figure 3 .

- Finally, from vehicle sizes, the average $\mathrm{CO}_{2}$ emissions per $\mathrm{km}$ and hence the approximate fuel efficiency for each broad car category were determined from the excise duty bands.

It is worth noting that the behavioural data so extracted are representative of the whole UK population and are not specific to early adopters. It is possible that by 2030 a significant fraction of electric vehicle users will still fall in the category of so-called early adopters and we acknowledge the limitations of our study in this respect. However, because the focus of the study is not on assessing possible market entry routes for electric vehicles, rather on comparing the total cost of ownership of different types of electric powertrains in mainstream markets, we believe that this limitation does not fundamentally undermine the validity of our results.

${ }^{\mathrm{d}}$ These are all households that failed to fully complete the above-mentioned 7-day travel diary

e When merging data files, the keyed table is the file in which data can be applied to multiple cases in the other data file. In particular, the "vehicle" data file contains information on vehicles which have been used for several trips, or cases in the "journey" data file. In other words, each trip is associated to a vehicle, but a vehicle is usually associated to more than one trip. Identifying the keyed table where relevant is necessary in order to ensure that the data files are correctly matched. 


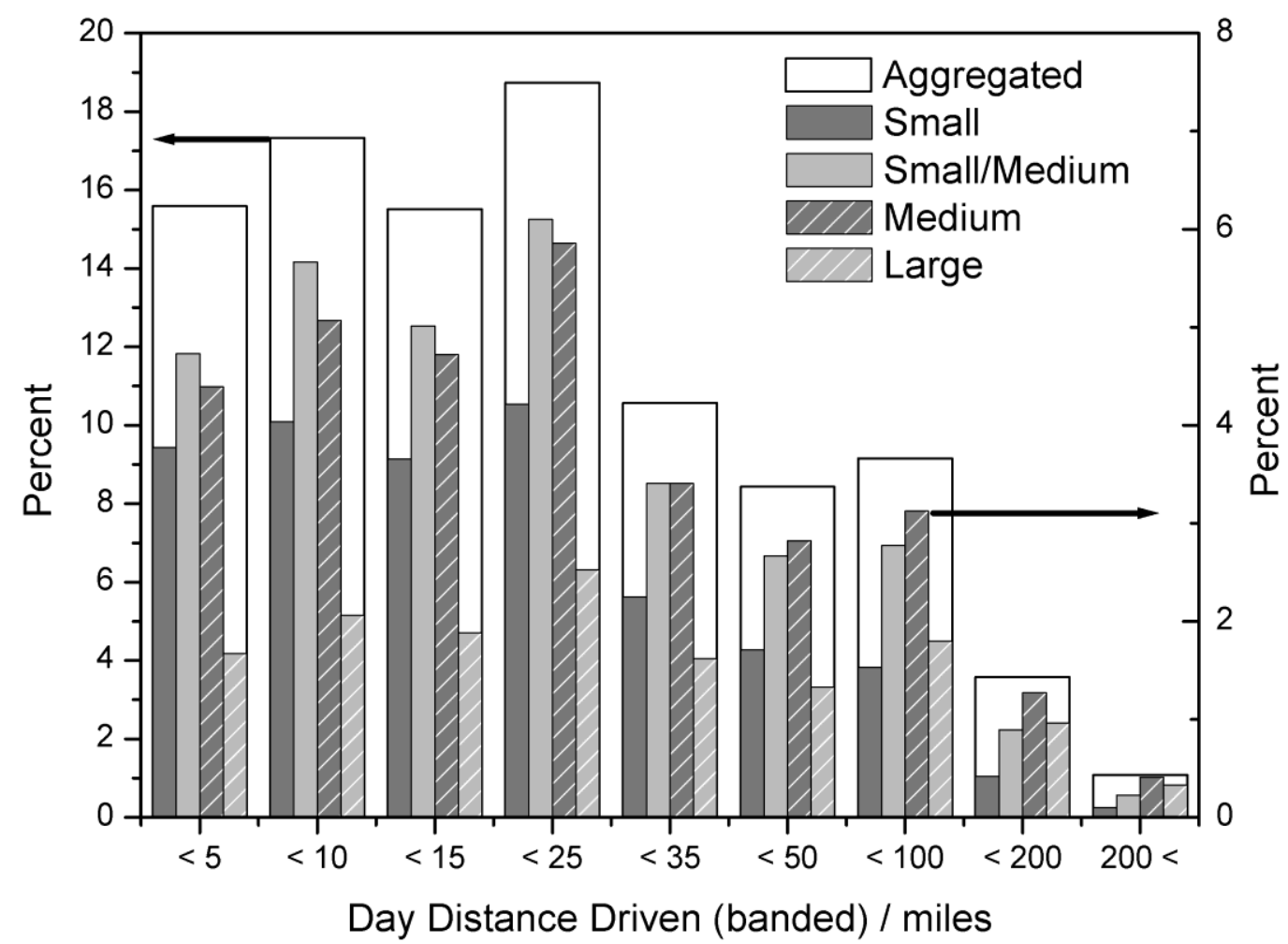

Figure 3. Data extracted from the UK National Travel Survey, showing the aggregated average daily distance travelled by private car in white with the axis on the left, and the breakdown of average daily distance by car types shown in various labelled shades of grey with the axis on the right

\section{Cost prediction analysis}

The technology cost predictions for fuel cells (IEA 2007) and hydrogen production and distribution (IEA 2007) provided by the International Energy Agency (IEA) are considered to be a reasonable assessment of the prospects for hydrogen fuel cells in a mass production scenario.

A report published by BERR and the DfT in the UK (DfT 2008) includes an assessment of the cost and performance requirements for BEVs and plug in hybrid EVs, and also includes an assessment of the current and projected costs of lithium ion battery technologies.

The IEA cost predictions for fuel cells (IEA 2007) assume a technology learning rate of between 0.78 and 0.85 , equivalent to cost reductions of $22 \%$ and $15 \%$, respectively, with each doubling of cumulative production. Justification for the costs of individual components of the fuel cell powertrain is described in detail by the IEA. The IEA predictions suggest that a fuel cell system cost of $\$ 35-75 \mathrm{~kW}_{\mathrm{e}}{ }^{-1}$ should be anticipated by 2030 ; the underlying assumption being that fuel cells by then would be mass manufactured. Adding the costs of the electric powertrain and hydrogen storage, an $80 \mathrm{~kW}$ fuel cell powertrain in 2030 would cost $\$ 4.9 \mathrm{k}-\$ 10 \mathrm{k}$ compared to $\$ 2.4 \mathrm{k}-\$ 2.5 \mathrm{k}$ for a conventional $80 \mathrm{~kW}$ ICE powertrain. However, these predictions are based upon a crucial assumption, that the fuel cell system must provide the peak power of the vehicle.

In this analysis the capital cost of the powertrain and the fuel cost at point of sale of the various fuel options are compared. Any mark-up that may be applied at the point of sale, such as profit, inflation, taxes, fuel duty, and cost of capital have been excluded. However a cost for carbon dioxide emissions is included. This enables the technologies to be evaluated on a level playing field representing the marketplace in 2030. However, in this paper, all costs are relative to 2010, and exchange rates of 0.7 GBP equals 1 USD and 1 GBP equals 1 Euro have been used to compare reports prepared in different currencies. 
This is a pre-print version of: Offer, G.J., et al., Techno-economic and behavioural analysis of battery electric, hydrogen fuel cell and hybrid vehicles in a future sustainable road transport system in the UK. Energy Policy (2011), doi:10.1016/j.enpol.2011.01.006

\subsection{Capital cost}

The key assumptions that have been made are summarised in table 2:

- The IEA cost predictions used for the fuel cell and conventional powertrains in 2030 (IEA 2007) are summarised in table 2.

- In order to compare to the IEA cost predictions, a baseline vehicle platform is assumed with the following requirements:

- $80 \mathrm{~kW}_{\mathrm{e}}$ peak power (as used by the IEA (IEA 2007))

- $20 \mathrm{~kW}_{\mathrm{e}}$ mean power, estimated based on a saloon car with a frontal area of $2.2 \mathrm{~m}^{2}$, drag coefficient of 0.35 cruising at $70 \mathrm{mph}$ with an appropriate rolling resistance, which equals roughly $1 \mathrm{MJ}^{\text {mile }}{ }^{-1}$ at a constant speed of $70 \mathrm{mph}$

- Different vehicle platforms for different vehicle types are shown in table 6.

- The FCHEV was assumed to be a plug in hybrid with the capability to recharge the batteries overnight and a hydrogen fuel cell range extender

- For the baseline vehicle platform the battery sizes considered and the related utility factors are summarised in Table 1 and shown in figure 4. Revised data for different vehicle sizes are shown in figure 12.

- Battery costs of $\$ 300 \mathrm{kWh}^{-1}$ were assumed for the 2030 pessimistic scenario based upon the projections for 2020 (DfT 2008)

- Battery costs of $\$ 200 \mathrm{kWh}^{-1}$ were assumed for the 2030 optimistic scenario assuming some improvement on the predictions for 2020 (DfT 2008)

- It is assumed that these cost predictions are for the useable state of charge (SOC) of the battery.

Table 1. Summary of the average behavioural data extracted from the UK National Travel Survey and calculated battery size for specified ranges

\begin{tabular}{|c|c|c|c|c|c|c|c|}
\hline $\begin{array}{l}\text { Day } \\
\text { distance } \\
\text { (miles) }\end{array}$ & Frequency & $\begin{array}{l}\text { Cumulative } \\
\text { percentage } \\
\text { journeys }\end{array}$ & $\begin{array}{l}\text { Average } \\
\text { journey } \\
\text { distances } \\
\text { (miles) }\end{array}$ & $\begin{array}{l}\text { Total miles } \\
\text { (=average } \\
\text { journey } \\
\text { distances * } \\
\text { frequency) }\end{array}$ & $\begin{array}{l}\text { Battery } \\
\text { size }^{1} \\
(\mathrm{kWh})\end{array}$ & $\begin{array}{l}\text { Percentage } \\
\text { miles } \\
\text { within AER } \\
2\end{array}$ & $\begin{array}{l}\text { Percentag } \\
\text { e miles } \\
\text { driven on } \\
\text { electricity }^{3}\end{array}$ \\
\hline$<5$ & 33,988 & $15.6 \%$ & 2.87 & 97,508 & 1.37 & $1.62 \%$ & $16.9 \%$ \\
\hline $5<10$ & 37,783 & $32.9 \%$ & 7.02 & 265,361 & 2.74 & $6.04 \%$ & $30.3 \%$ \\
\hline $10<15$ & 33,812 & $48.4 \%$ & 11.9 & 403,865 & 4.11 & $12.8 \%$ & $40.8 \%$ \\
\hline $15<25$ & 40,853 & $67.2 \%$ & 19.3 & 789,978 & 6.86 & $25.9 \%$ & $55.6 \%$ \\
\hline $25<35$ & 23,048 & $77.8 \%$ & 29.4 & 677,397 & 9.60 & $37.2 \%$ & $65.4 \%$ \\
\hline $35<50$ & 18,364 & $86.2 \%$ & 41.1 & 754.140 & 13.7 & $49.7 \%$ & $74.7 \%$ \\
\hline $50<100$ & 19,961 & $95.3 \%$ & 67.3 & $1,343,548$ & 27.4 & $72.1 \%$ & $88.9 \%$ \\
\hline $100<200$ & 7,796 & $98.9 \%$ & 135 & $1,054,768$ & 54.9 & $89.6 \%$ & $97.4 \%$ \\
\hline $200<$ & 2,356 & $100.0 \%$ & 266 & $625,994,90$ & 82.3 & $100.0 \%$ & $100.0 \%$ \\
\hline
\end{tabular}




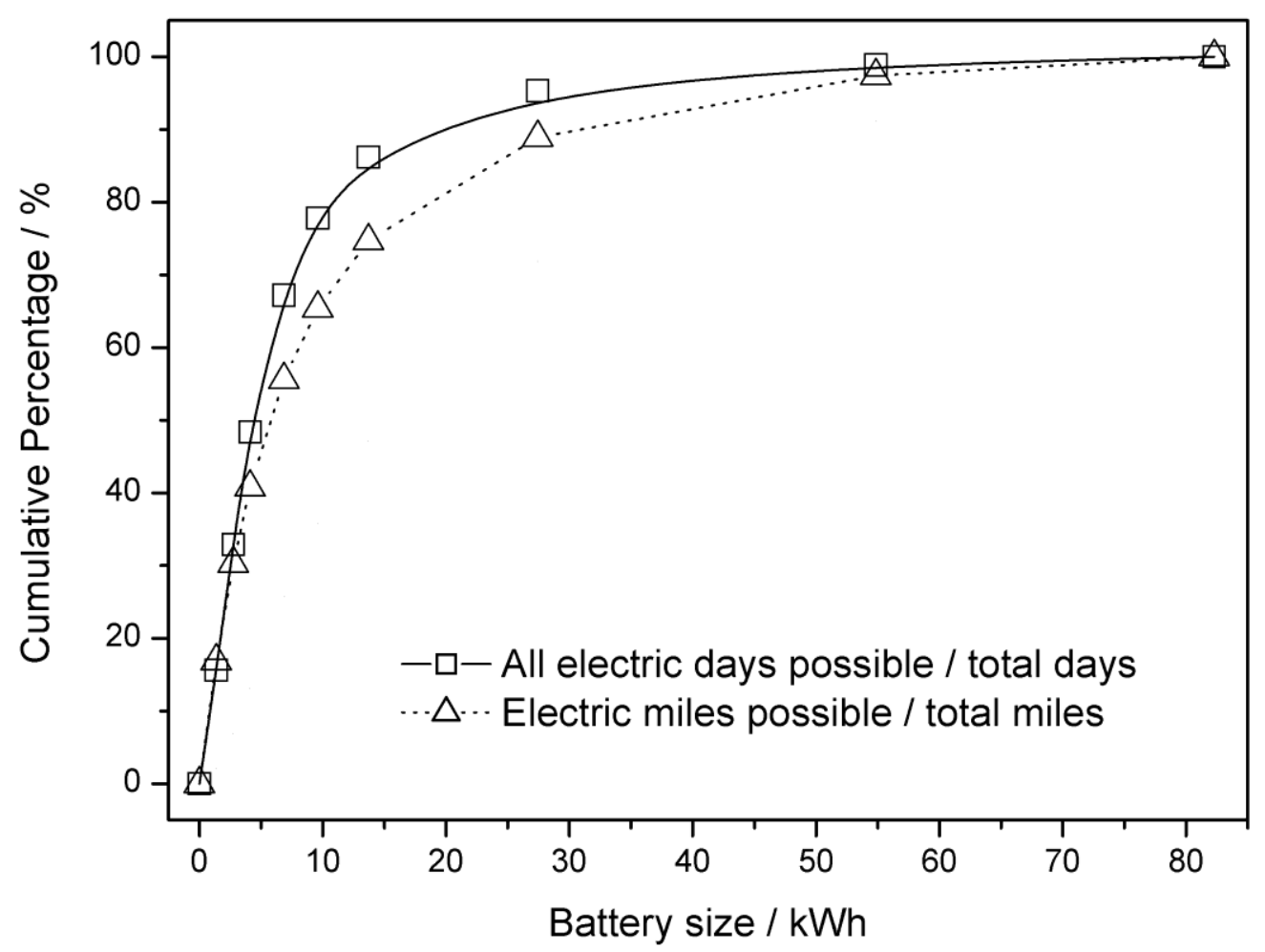

Figure 4. Battery size and percentage of miles that can be driven on electrical power calculated from data extracted from the UK National Travel Survey. The utility factors that are shown are similar to those reported by (Kromer and Heywood 2008) for a plug-in-hybrid with a 60 mile range and those of (Bradley and Quinn 2010).

Table 2. Summary of the capital cost input data for 2030

\begin{tabular}{lccc}
\hline Powertrain cost & Minimum & Maximum & Average \\
\hline Fuel cell $\$ / \mathrm{kW}_{\mathrm{e}}$ & $\$ 35^{2}$ & $\$ 75^{2}$ & $\$ 55$ \\
\hline Battery $\$$ / kWh & $\$ 200$ & $\$ 300$ & $\$ 250$ \\
\hline Electric drive train & $\$ 1,200^{1}$ & $\$ 2,030^{1}$ & $\$ 1,615$ \\
\hline Hydrogen storage & $\$ 900^{1}$ & $\$ 2,000^{1}$ & $\$ 1,450$ \\
\hline Conventional (ICE) & $\$ 2,400^{1}$ & $\$ 2,530^{1}$ & $\$ 2,465$
\end{tabular}

denotes those used from the IEA report (IEA 2007),

${ }^{2}$ denotes those adapted from the IEA report (IEA 2007)

\subsection{Running cost}

In order to assess the viability of the various powertrains it is necessary to consider not just the capital cost but also the running costs. The key assumptions that have been made are summarised in Table 3: 
- It is difficult to obtain an accurate picture of future hydrogen costs, because these would depend on the location, on the technology and scale of production, and also on the transmission and distribution method. In addition the costs are inherently coupled to the costs of the primary energy source or feedstock from which the hydrogen is produced, and this further complicates matters due to price variability. The cost in 2030 is assumed to be between $\$ 8 \mathrm{~kg}^{-1}$ (pessimistic) assuming production by electrolysis (Haryanto, Fernando et al. 2005) and $\$ 2 \mathrm{~kg}^{-1}$ (optimistic) $\left(\$ 56 \mathrm{GJ}^{-1}\right.$ and $\$ 14 \mathrm{GJ}^{-1}$ respectively) assuming production by steam reforming of natural gas using the IEA cost predictions (IEA 2007).

- The cost of gasoline in 2030 is assumed to be between $\$ 6$ gallon $^{-1}$ and $\$ 3$ gallon $^{-1}$ (\$38 GJ 1 and $\$ 19 \mathrm{GJ}^{-1}$ respectively) for the pessimistic and optimistic scenarios respectively.

- Cost estimates for electricity generation vary widely and also seem to be highly subjective. A review of the unit cost estimates by the UK Energy Research Centre (UKERC) is used. The current (2010) cost of electricity is assumed to be $\$ 45 \mathrm{MWh}^{-1}$ (equivalent to $\$ 12.6 \mathrm{GJ}^{-1}$ ) based upon the UKERC assessment for the predominant technologies of coal, gas and nuclear. Wind is $\$ 56.5 \mathrm{MWh}^{-1}$ (Heptonstall 2007) (equivalent to $\$ 15.7 \mathrm{GJ}^{-1}$ ). Therefore the current cost of wind energy is used as the pessimistic assumption for 2030. The 2030 optimistic scenario is arbitrary and assumes a $25 \%$ reduction in costs to $\$ 34 \mathrm{MWh}^{-1}$ (equivalent to $\$ 9.4 \mathrm{GJ}^{-1}$ ). However, this does not represent the cost of delivery and transmission and this must be taken into account. The retail cost of electricity in the UK as reported by Eurostat in 2008 (Eurostat date of extraction: October 2008) was $\$ 129 \mathrm{MWh}^{-1}$ (equivalent to $\$ 36 \mathrm{GJ}^{-1}$ ) without tax for high usage residential users, a factor of 2.85 increase in cost. Therefore a fixed ratio of 2.85 was applied to the production cost predictions to generate the retail cost predictions.

- None of the cost assumptions include subsidies, taxes or local charges, allowing other policy measures such as feed-in tariffs and local taxation to be ignored.

- In the previous paper a conventional powertrain efficiency of $40 \mathrm{mpg}$ was assumed, equivalent to $4 \mathrm{MJ}$ mile $^{-1}$ (Offer, Howey et al. 2010). However, vehicle downsizing and improvements in ICE engines together with hybridisation are expected to improve the efficiency of conventional vehicles significantly by 2030 (McKinsey 2010). As such an improvement of $35 \%$ in efficiency of the baseline vehicle is assumed, to $54 \mathrm{mpg}$, equivalent to $2.9 \mathrm{MJ}$ mile $^{-1}$.

- The fuel cell powertrain is assumed to be by 2030 twice as efficient as the conventional powertrain (Burke 2007), i.e. $108 \mathrm{mpg}, 97$ miles $\mathrm{kg}^{-1}$ of hydrogen, or $1.5 \mathrm{MJ}$ mile ${ }^{-1}$. Any possible hydrogen losses from the tank or other parts of the powertrain are not accounted for in this study.

- The battery powertrain is assumed to be by 2030 four times as efficient, i.e. $216 \mathrm{mpg}, 4.9$ miles $\mathrm{kWh}^{-1}$, or $0.7 \mathrm{MJ}$ mile ${ }^{-1}$ which is also consistent with (Burke 2007). The effect of battery weight on overall vehicle fuel economy was not taken into account; however it is clear that for larger battery packs this would not be negligible.

- Different energy consumptions per mile for different vehicle types are shown in table 6

- A single overnight battery charge is assumed for both the BEV and FCHEV, for the reasons previously explained (see footnote c).

- Finally, the lifecycle of the vehicle was assumed to be 109,000 miles. This is based upon the average mileage driven in the UK in 2008 of 8,265 miles (2008) and the average age of "scrappage" for a UK car in 2007 of 13.2 years (2007).

The assumptions for the energy cost of gasoline are very similar to those used by Granovskii et al. (Granovskii, Dincer et al. 2006) who compared conventional, hybrid, electric and fuel cell vehicles (but not fuel cell hybrid vehicles), but assumptions for hydrogen and electricity cost are much higher than those used by Granovskii et al. (Granovskii, Dincer et al. 2006). This is because in this study all the costs associated with delivering the fuel to the consumer, rather than just the production costs, have been included.

Assumptions for fuel consumption are slightly better than those used by Granovskii et al. who assumed a range of 262, 480 and 925 miles $\mathrm{GJ}^{-1}$ compared to our 342, 684 and 1367 miles 
This is a pre-print version of: Offer, G.J., et al., Techno-economic and behavioural analysis of battery electric, hydrogen fuel cell and hybrid vehicles in a future sustainable road transport system in the UK. Energy Policy (2011), doi:10.1016/j.enpol.2011.01.006

$\mathrm{GJ}^{-1}$ for gasoline, hydrogen and electric powered vehicles respectively. An inherent assumption is that the energy consumption per mile for each journey type is the same regardless of journey length or driving behaviour. The sensitivity of the result to this assumption will be explored in further papers.

Table 3. Summary of the running cost input data for 2030 , normalised to $\$ \mathrm{GJ}^{-1}$ for comparison

\begin{tabular}{llllll}
\hline Fuel cost & Minimum & Maximum & Average & miles $\mathrm{GJ}^{-1}$ & typical units \\
\hline Gasoline & $\$ 19 \mathrm{GJ}^{-1}$ & $\$ 38 \mathrm{GJ}^{-1}$ & $\$ 28.5 \mathrm{GJ}^{-1}$ & 342 & $54 \mathrm{mpg}$ \\
\hline Hydrogen & $\$ 14 \mathrm{GJ}^{-1}$ & $\$ 56 \mathrm{GJ}^{-1}$ & $\$ 35 \mathrm{GJ}^{-1}$ & 684 & $97 \mathrm{miles} \mathrm{kg}^{-1}$ \\
\hline Electric & $\$ 27 \mathrm{GJ}^{-1}$ & $\$ 45 \mathrm{GJ}^{-1}$ & $\$ 36 \mathrm{GJ}^{-1}$ & 1367 & $4.9 \mathrm{miles} \mathrm{kWh}^{-1}$ \\
\hline
\end{tabular}

\subsection{Carbon dioxide emissions}

In order to assess the carbon dioxide emissions of the various powertrains it is necessary to consider the carbon dioxide emissions associated with the fuel. The key assumptions that have been made are summarised in Table 4.

- Electricity carbon dioxide emissions are assumed to be $150 \mathrm{gCO}_{2} \mathrm{MJ}^{-1}$ based upon the 2008 UK average electricity emissions of $540 \mathrm{gCO}_{2} \mathrm{kWh}^{-1}$ which included $5.5 \%$ of electricity generation from renewables. Electricity is assumed to be $50 \%$ decarbonised by 2030 which would equal $79 \mathrm{gCO}_{2} \mathrm{MJ}^{-1}$

- Petrol carbon dioxide emissions are assumed to be $77.6 \mathrm{gCO}_{2} \mathrm{MJ}^{-1}$ based upon the chemical composition of the fuel and a calorific value of $34.8 \mathrm{MJ}^{\mathrm{Litre}^{-1}}$

- Hydrogen carbon dioxide emissions are assumed to be $76.9 \mathrm{gCO}_{2} \mathrm{MJ}^{-1}$ based upon a value of $11 \mathrm{kgCO}_{2} \mathrm{~kg} \mathrm{H}_{2}^{-1}$ for steam reforming natural gas and a calorific value of $143 \mathrm{MJ} \mathrm{kg} \mathrm{H}_{2}^{-1}$ and the assumption that hydrogen will predominately be manufactured by steam reforming natural gas in 2030 (Yeh, Loughlin et al. 2006)

It has not been possible to include the lifecycle carbon dioxide emissions, because accurate data for the emissions incurred during the manufacturing and assembly of FCV, FCHEV and BEVs are not available. Therefore this study only takes into account the emissions produced by driving the vehicle.

In addition in this study the decarbonisation of electricity generation was assumed to be $50 \%$, but considering that the installed capacity in 2030 is unlikely to be affected by the number of electric vehicles, but a significant number of electric vehicles could affect the total capacity needed, this assumption is highly uncertain. The target for 2050 is ostensibly to decarbonise electricity generation entirely (CCC 2008), with a target of $40 \%$ by 2020 (DECC 2009), but both will be challenging if a significant penetration of electric vehicles is achieved. Consider if all private vehicles in the UK are plug-in vehicles of some type by 2030; this would be 30 million vehicles, and that they have an average battery size of $10 \mathrm{kWh}$, and they all recharge every day. This would enable them to operate on electric power for $65 \%$ of miles driven, and reduce emissions by at least $34-45 \%$ (even with current electricity generation and an ICE as the range extender), but would require roughly 100 TWh of electricity, or $35 \mathrm{GW}$ average continuous during an 8 hour overnight charging period, not taking into account transmission and recharging losses. The effect of this on targets to decarbonise electricity generation are currently unknown, therefore the sensitivity of changes to this assumption was tested separately using an upper and lower estimate of $20 \%$ and $80 \%$, as summarised in Table $5.20 \%$ and $80 \%$ were selected to represent a range based upon a business as usual scenario and extrapolations of UK targets.

Production emissions for petrol have not been taken into account, however these may be highly impacted by decreasing quality of crude oil and the increasing use of unconventional sources of oil. Therefore the comparison with petrol presented here represents tailpipe only and should be taken in that context. 
This is a pre-print version of: Offer, G.J., et al., Techno-economic and behavioural analysis of battery electric, hydrogen fuel cell and hybrid vehicles in a future sustainable road transport system in the UK. Energy Policy (2011), doi:10.1016/j.enpol.2011.01.006

Table 4.

Summary of $\mathrm{CO} 2$ emissions for each fuel

\begin{tabular}{llll}
\hline & Petrol & Hydrogen & Electricity (2008) \\
\hline $\mathrm{CO}_{2}$ emissions $/ \mathrm{gCO}_{2} \mathrm{MJ}^{-1}$ & 77.6 & 76.9 & 150 \\
\hline Fuel consumption $/ \mathrm{MJ}$ mile & 2.93 & 1.46 & 0.73 \\
\hline Emissions $/ \mathrm{gCO}_{2} \mathrm{mile}^{-1}$ & 227 & 112 & 110 \\
\hline Emissions $/ \mathrm{gCO}_{2} \mathrm{~km}^{-1}$ & 142 & 70 & 68 \\
\hline
\end{tabular}

Table 5.

Summary of other key assumptions which are not included in the error bars of the baseline model

\begin{tabular}{llll}
\hline & Minimum & Average & Maximum \\
\hline Lifetime mileage & $\mathrm{n} / \mathrm{a}$ & 109,000 & $\mathrm{n} / \mathrm{a}$ \\
\hline $\mathrm{CO}_{2}$ cost per Tonne & $\$ 49$ & $\$ 191$ & $\$ 120$ \\
\hline $\begin{array}{l}\text { Decarbonisation of } \\
\text { electricity generation }\end{array}$ & $20 \%$ & $50 \%$ & $80 \%$ \\
\hline Charging & $\mathrm{n} / \mathrm{a}$ & & $\mathrm{n} / \mathrm{a}$ \\
\hline
\end{tabular}

\subsubsection{Cost of carbon}

It is highly subjective to set an appropriate carbon price for this study. In the report published by the US Energy Information Administration in response to a question about the American Clean Energy and Security Act of 2009 it was estimated that the price of carbon would be between $\$ 41$ and $\$ 191$ by 2030 .

These values were used in this paper, therefore an average carbon price of $\$ 120$ per Tonne of $\mathrm{CO}_{2}$ in 2030 was assessed. The sensitivity of changes to this cost separately using an upper and lower estimate of $£ 191$ and $\$ 41$ per Tonne of $\mathrm{CO}_{2}$ respectively, as summarised in Table 5 , were also tested.

\subsection{Vehicle type}

In order to include the behavioural data for different vehicle types in the model it is necessary to adjust the powertrain assumptions and fuel consumption assumptions for each vehicle type. This is not straightforward as the vehicle type definitions do not include this data. Carbon dioxide emissions from different market segments (2004) were taken and matched with the vehicle types in the National Travel Survey (NTS). The NTS medium vehicle was matched with the multipurpose market segment which had average emissions of $190 \mathrm{gCO}_{2} \mathrm{~km}^{-1}$ - a very close match to the assumptions in 2010 made here, of $40 \mathrm{mpg}$ emitting $192 \mathrm{gCO}_{2} \mathrm{~km}^{-1}$ for the baseline scenario. The NTS small vehicle was matched with the super-mini market segment which had average emissions of $150 \mathrm{gCO}_{2} \mathrm{~km}^{-1}$. The NTS small/medium vehicle was matched with the lower medium market segment which had average emissions of $170 \mathrm{gCO}_{2} \mathrm{~km}^{-1}$. The NTS large vehicle was matched with the luxury market segment which had average emissions of $275 \mathrm{gCO}_{2} \mathrm{~km}^{-1}$. A linear relationship between the powertrain assumptions (i.e. fuel cell and battery size) and energy consumption and the average emissions for the market segment was assumed. The data used in the model, adjusted to reflect the $35 \%$ improvement in efficiency by 2030 , is shown in table 6 . 
This is a pre-print version of: Offer, G.J., et al., Techno-economic and behavioural analysis of battery electric, hydrogen fuel cell and hybrid vehicles in a future sustainable road transport system in the UK. Energy Policy (2011), doi:10.1016/j.enpol.2011.01.006

Table 6. Adjusted powertrain and energy consumption assumptions for different vehicle types

\begin{tabular}{llllll}
\hline National Travel Survey & Small & $\begin{array}{l}\text { Small / } \\
\text { Medium }\end{array}$ & $\begin{array}{l}\text { Medium \& } \\
\text { Average }\end{array}$ & Large \\
\hline Market Segments & Super-mini & $\begin{array}{l}\text { Lower } \\
\text { medium }\end{array}$ & Multipurpose & Luxury \\
\hline Equivalent ICE mpg & 69 & 61 & 54 & 38 \\
\hline Equivalent ICE / MJ mile & 2.29 & 2.59 & 2.93 & 4.16 \\
\hline Equivalent ICE gCO km $^{-1}$ & 111 & 126 & 142 & 202 \\
\hline Peak power required / kW & 62.7 & 71 & 80 & 114 \\
\hline Average power required / kW & 15.7 & 17.8 & 20 & 29 \\
\hline $\mathrm{H}_{2}$ consumption / MJ mile ${ }^{-1}$ & 1.14 & 1.30 & 1.46 & 2.08 \\
\hline Electricity / MJ mile $^{-1}$ & 0.57 & 0.65 & 0.73 & 1.04 \\
\hline
\end{tabular}

\subsection{End-of-life cost}

End of life costs are not addressed in this study, nor is the durability and lifetime of the various components accounted for. Therefore it is implicitly assumed that the end-of-life costs are all equal, and that all components will have acceptable lifetimes. This is a very important consideration and must be addressed in order to accurately predict complete lifecycle costs, but at the present time there is insufficient reliable data on the recycling and/or disposal costs of vehicle batteries and fuel cells to make an objective assessment.

\subsection{Sensitivity Analysis}

As in the previous paper, assumptions were tested using a sensitivity analysis. This is presented in this paper as error bars which describe the maximum and minimum result possible within the boundaries of the assumptions. Error bars shown in all figures include the variations in cost assumptions for powertrain capital cost shown in Table 2, and fuel costs shown in Table 3. The assumptions for costs shown in Table 5 and different usage pattern and powertrain configurations shown in table 6 are tested separately.

\section{Results and discussion}

\subsection{Results}

The data from the National Travel Survey can be combined with the baseline scenario model to generate the percentage of miles that can be driven exclusively on electrical power as shown in table 1 and figure 4.

The baseline study is presented in figure 5 . All results presented are for the 2030 scenario. The lifecycle costs tend towards a minimum for a plug-in hybrid with $2-5 \mathrm{kWh}$ battery size, and lifecycle costs of the FCHEV do not exceed the FCV costs until the battery size approaches 25 $\mathrm{kWh}$. The FCV is more expensive than the ICE unless the cost assumptions are lowered, but the FCHEV is always cheaper than the ICE as long as the battery size is less than approximately 15 $\mathrm{kWh}$. For the baseline scenario the largest lifecycle cost saving for the FCHEV with a battery size between 2-5 kWh is approximately $\$ 2,155$, a $19 \%$ saving. 
As shown in figure 6 when the cost of carbon dioxide emissions at $\$ 120$ tonne $^{-1}$ is included the lifecycle costs tend towards a minimum for a FCHEV with a battery size of between 3-7 kWh, and the FCHEV costs do not exceed the FCV costs until the battery size approaches $25 \mathrm{kWh}$. This indicates that if the costs of carbon dioxide emissions are taken into account, larger battery sizes are favoured, and the primary cost advantage of a hybrid solution is the savings from downsizing the fuel cell. However, this result should be treated with caution as the carbon dioxide emissions during vehicle production have not been included.

In addition, the cost savings compared to the ICE are considerably greater when the costs of carbon dioxide emissions are included. The FCHEV is cheaper as long as the battery size is less than approximately $25 \mathrm{kWh}$, and for the baseline scenario the largest cost saving for the FCHEV with a battery size between $3-7 \mathrm{kWh}$ is approximately $\$ 3,945$, a $27 \%$ saving.

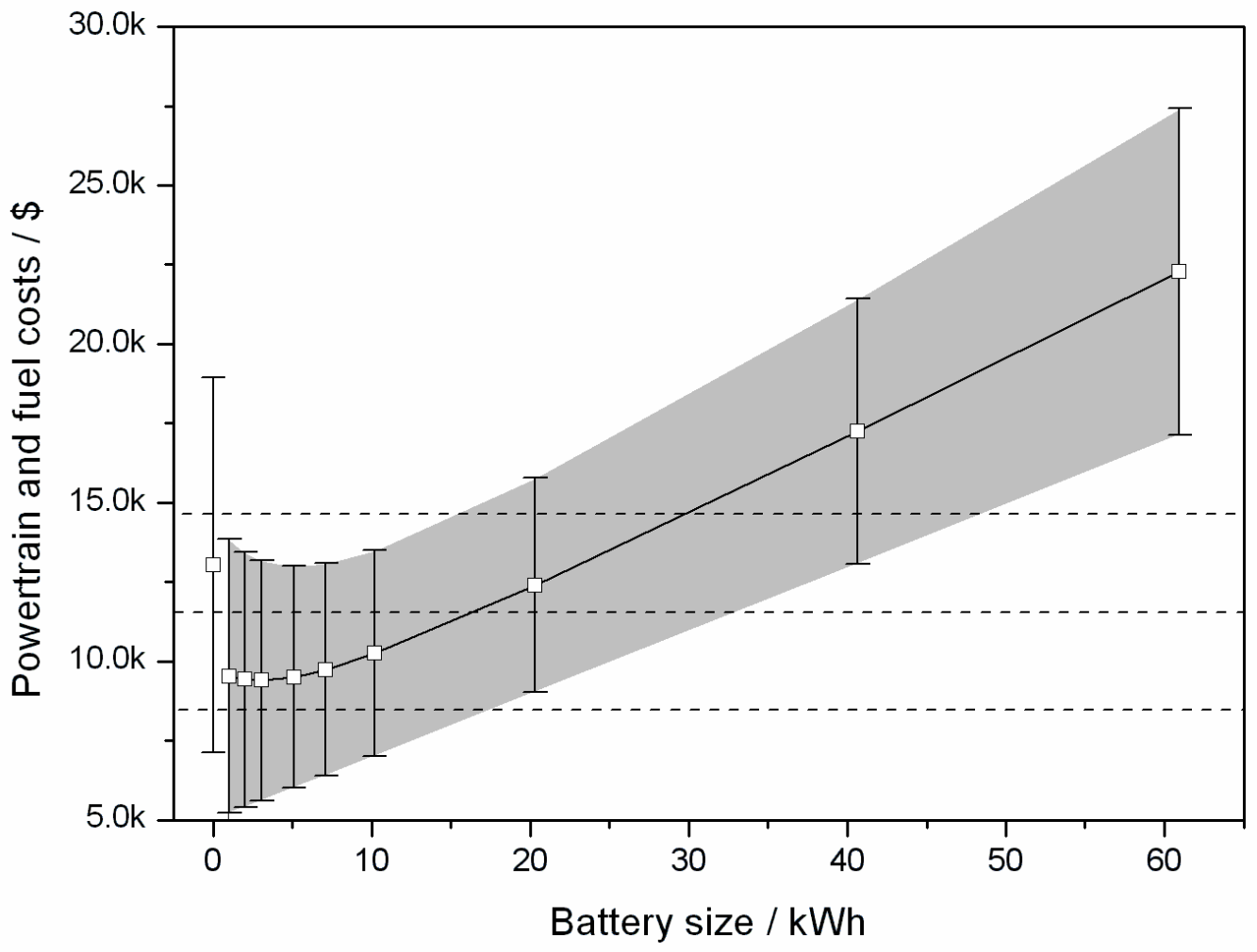

Figure 5. Baseline study of a fuel cell plug-in hybrid vehicle in 2030 with all assumptions set to average (口) and the boundaries of the assumptions shown as error bars within the grey shaded area. The baseline costs for a petrol ICE with low, average and high cost assumptions are shown as dashed lines 


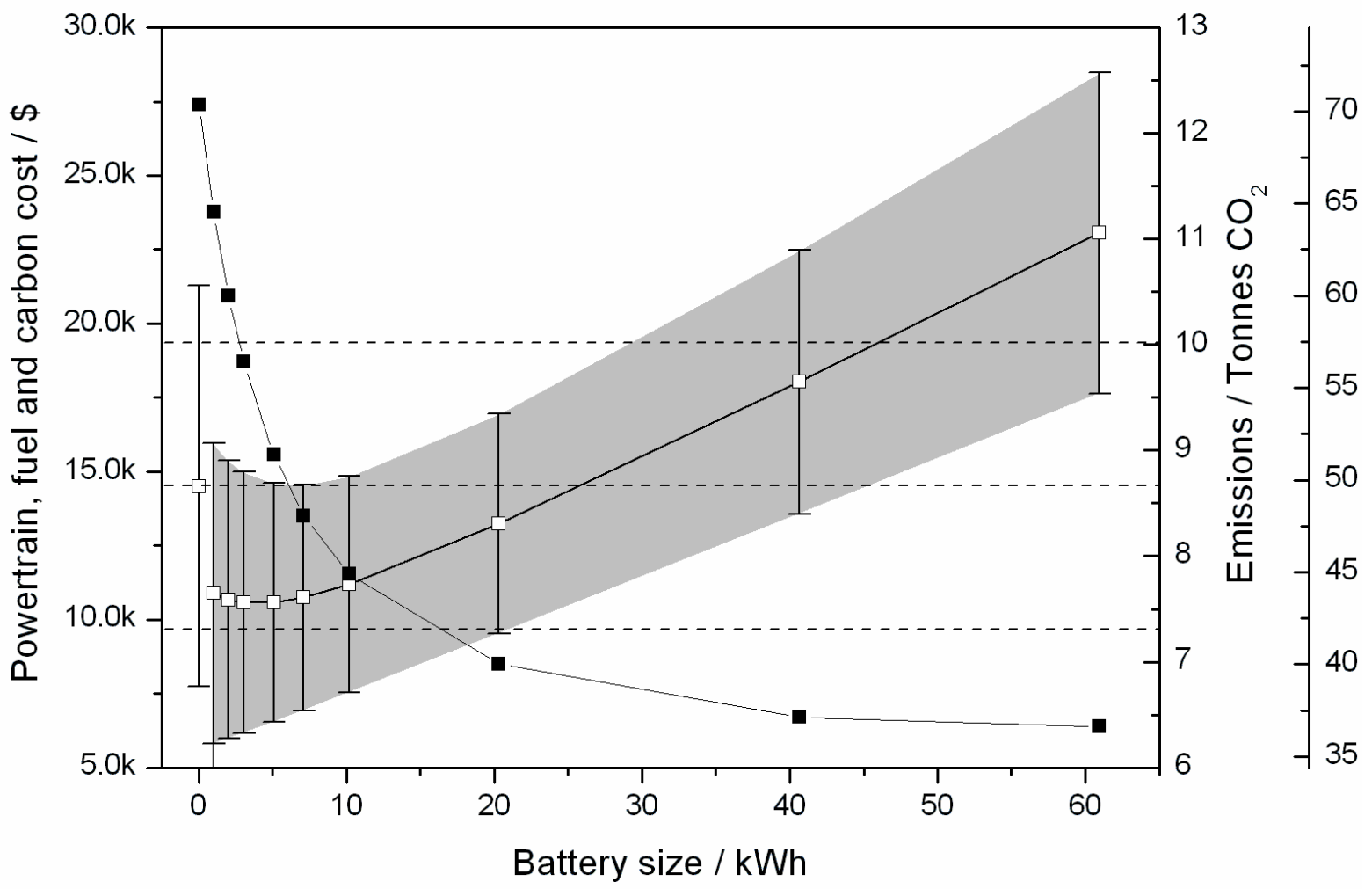

Figure 6. The same as figure 5 but including the cost of carbon dioxide at $\$ 120$ tonne- 1 for the carbon dioxide emissions from the vehicle and fuel production. The baseline cost for a petrol ICE with low, average and high cost assumptions are shown as dashed lines. The carbon dioxide emissions for the FCV and FCHEV are overlaid ( $\mathbf{\square})$ with the axis on the right.

\subsubsection{Battery cost}

The assumption for battery costs is between $\$ 200-300 / \mathrm{kWh}$, and as shown in figure 7 it can be seen that the capital cost of the batteries becomes the dominant factor above $25 \mathrm{kWh}$. As an additional test the battery cost was lowered to $\$ 100 / \mathrm{kWh}$, described as 'ultra low', keeping all other costs the same, and is also shown in figure 7. It can be seen that lowering the battery cost to $\$ 100 \mathrm{kWh}$ favours larger batteries, with the lowest overall cost between 7-20 kWh, enabling the vehicle to be operated as a BEV for around $86 \%$ of days, and $75 \%$ of miles driven (assuming a 10 $\mathrm{kWh}$ battery pack). If the fuel cell range extender is removed for the vehicles with 41 and $61 \mathrm{kWh}$ battery packs the costs are only cheaper than the optimum hybrid if the battery costs are $\$ 100$ $/ \mathrm{kWh}$ or less as shown in figure 7. This suggests that in 2030 the economics of BEVs as standalone solutions (i.e. rather than with range extenders) may not make sense unless the costs of batteries approach $\$ 100 \mathrm{kWh}$. In addition, the BEV option may have to overcome "range anxiety", an issue not considered in this paper but which constitutes an additional constraint when compared to hybrid vehicles.

This result is commensurate with the IEA Technology Roadmap for electric and plug-in hybrid electric vehicles (IEA 2009) which noted that in order to achieve a break-even cost with ICEs, battery costs must be reduced down to between $\$ 300-400$ per kWh by 2020 or sooner. 


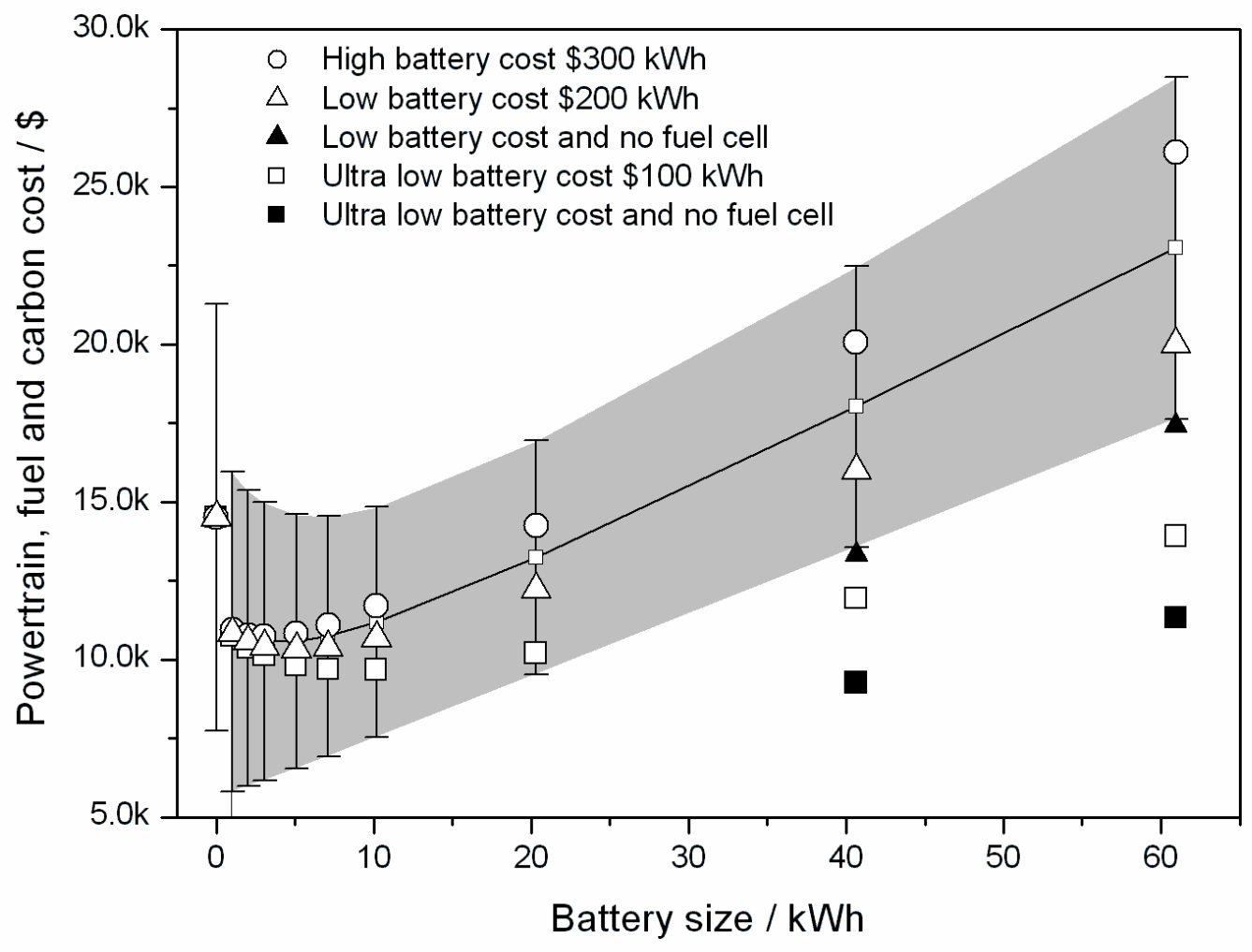

Figure 7. Sensitivity to battery cost with battery cost assumptions set high $(\circ)$, low $(\Delta)$, and ultra low ( $\square$ ), and without a fuel cell and battery cost assumptions set low $(\mathbf{\Lambda})$ and ultra low ( $\mathbf{\square})$

\subsubsection{Fuel Cell costs}

Varying the assumptions for fuel cell costs as shown in figure 8 does not change the result appreciably, as the minimum in both cases is for a FCHEV with a battery size between 4-10 kWh. However, it does change the battery size at which the lifecycle costs of the FCHEV exceed the FCV, from approximately $20 \mathrm{kWh}$ for low fuel cell cost assumptions to approximately $35 \mathrm{kWh}$ for high fuel cell cost assumptions. 


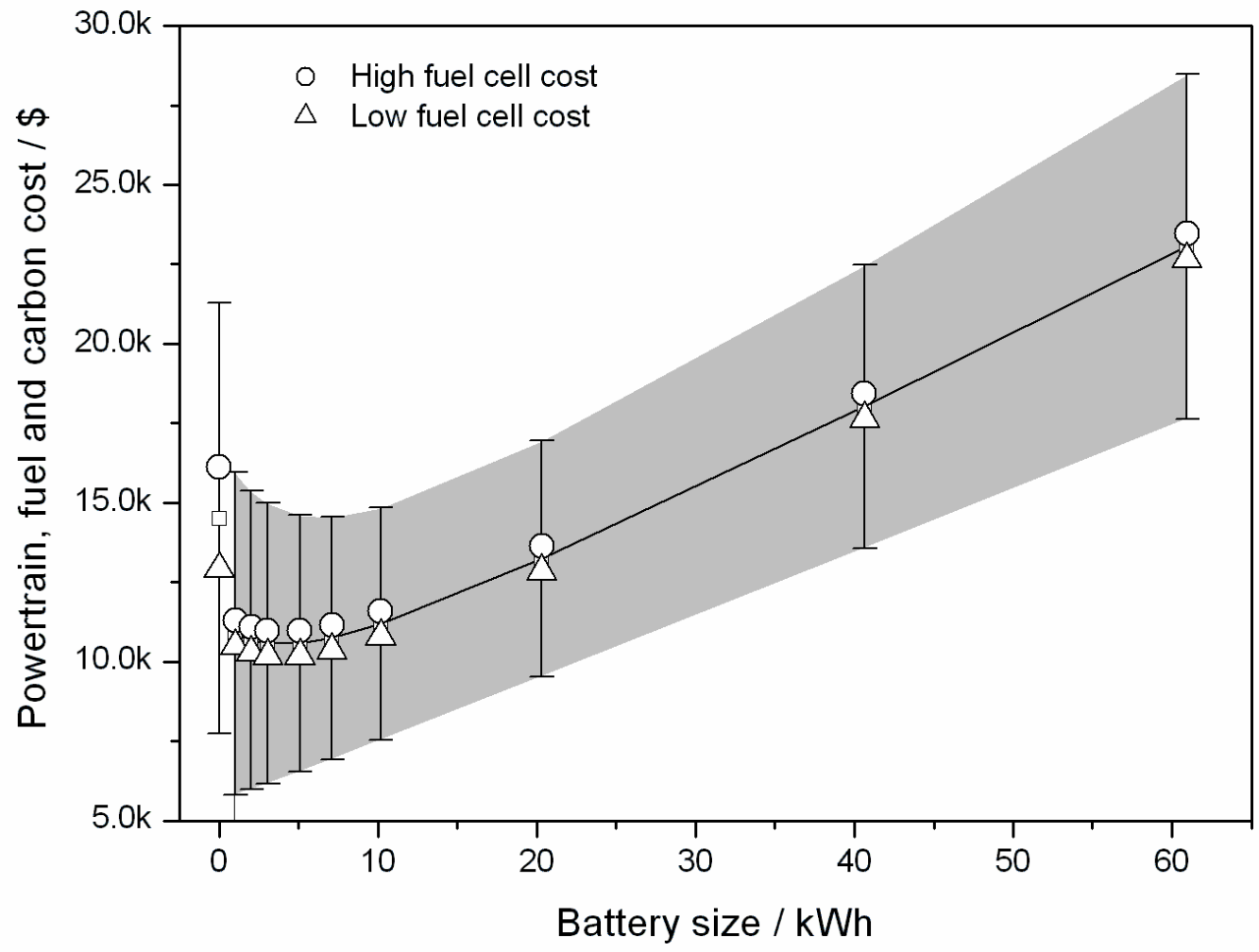

Figure 8. Sensitivity to fuel cell cost with fuel cell cost assumptions set high $(0)$ and low $(\Delta)$

\subsubsection{Decarbonisation of Electricity Generation}

In the previous paper it was demonstrated that the lifecycle costs were relatively insensitive to electricity cost (Offer, Howey et al. 2010), and this is also true here, therefore the effect of electricity cost variation is not presented separately. However, the extent of decarbonisation of electricity generation could affect the lifecycle costs if carbon dioxide is priced highly enough. Figure 9 shows the effect of reducing $\mathrm{CO}_{2}$ emissions from electricity generation by $20 \%, 50 \%$ and $80 \%$. With only $20 \%$ decarbonisation the emissions are only slightly less for the FCHEV as the FCV and the lifecycle costs reach a minimum for a small battery size between $2-5 \mathrm{kWh}$. However with $80 \%$ decarbonisation the emissions drop sharply and the lifecycle costs reach a minimum between 3-7 kWh. 


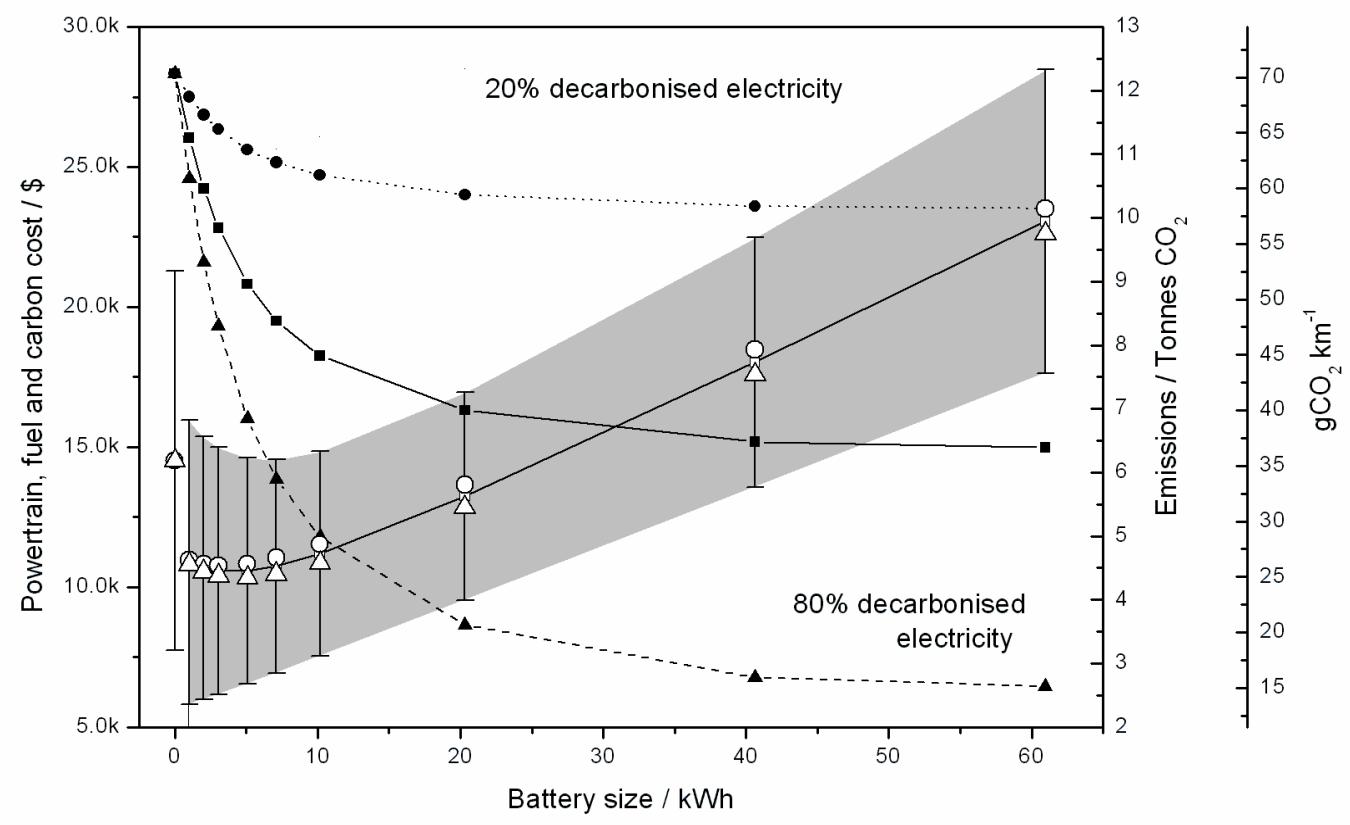

Figure 9. Sensitivity to the extent of the decarbonisation of the electricity generation with electricity decarbonisation assumptions set low $(\mathrm{O})$ and high $(\Delta)$. The carbon dioxide emissions are overlaid with the axis on the right and assumptions set low $(\bullet)$, average $(\boldsymbol{\bullet})$ and high $(\mathbf{\Delta})$

\subsubsection{Hydrogen cost}

As discussed earlier the hydrogen cost assumptions vary between $\$ 8 \mathrm{~kg}^{-1}$ assuming production by electrolysis (Haryanto, Fernando et al. 2005) and $\$ 2 \mathrm{~kg}^{-1}$ as the lower boundary of costs predicted by the IEA assuming production by steam reforming of natural gas (IEA 2007). In this study the effect of any $\mathrm{CO}_{2}$ emissions savings by using renewable electricity for electrolysis, and carbon capture and storage when steam reforming methane have not been included, and a constant value of $76.9 \mathrm{gCO}_{2} \mathrm{MJ}^{-1}$ is used. This is considered to be fair considering that $\mathrm{CO}_{2}$ emissions from hydrogen, assuming electrolysis using electricity that has been $80 \%$ decarbonised, would be roughly $64 \mathrm{gCO}_{2} \mathrm{MJ}^{-1}$ if the overall efficiency of electrolysing, compressing and delivering hydrogen is assumed to be $50 \%$. It was assumed that hydrogen from electrolysis will only occur if electricity is significantly decarbonised. However, in terms of cost it can be seen in figure 10 that the results are clearly sensitive ( $>50 \%$ uncertainty) to the cost of hydrogen for the FCHEV with a battery size of less than $10 \mathrm{kWh}$. A high hydrogen cost favours a FCHEV with a battery size between 5-10 kWh, and a low hydrogen cost favours a FCHEV with a battery size as small as possible (because the opportunity to plug-in delivers no value in terms of cost). 


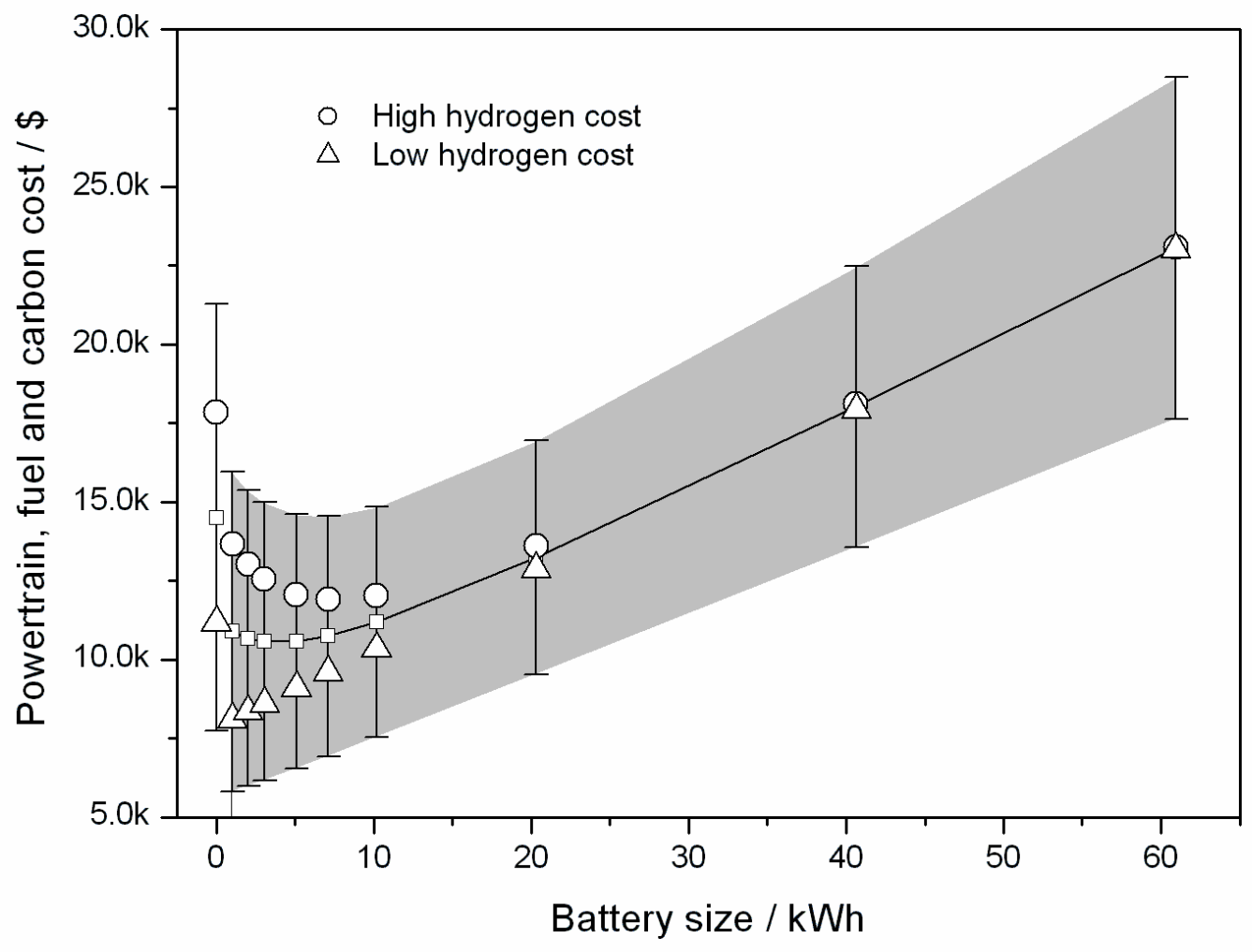

Figure 10. Sensitivity to hydrogen cost with hydrogen cost assumptions set high $(O)$ and low $(\Delta)$

\subsubsection{Cost per Tonne of Carbon Dioxide Emissions}

As discussed earlier the carbon dioxide emissions (carbon) cost assumptions vary between $\$ 49$ and $\$ 191$ per tonne of CO2 with the average set to $\$ 120$. The effect of varying the carbon cost is shown in figure 11, and it can be seen that this has little effect on the optimum battery size for the FCHEV, predicting between roughly 3-7 kWh. However the carbon cost does impose an offset on the results. Varying the carbon cost does have a large impact on the lifecycle cost of the petrol ICE vehicle which is also shown in figure 11, and this demonstrates as might be expected that carbon pricing is significant in this comparison, albeit only at relatively high levels. The case for adopting a FCHEV increases as carbon cost increases. 


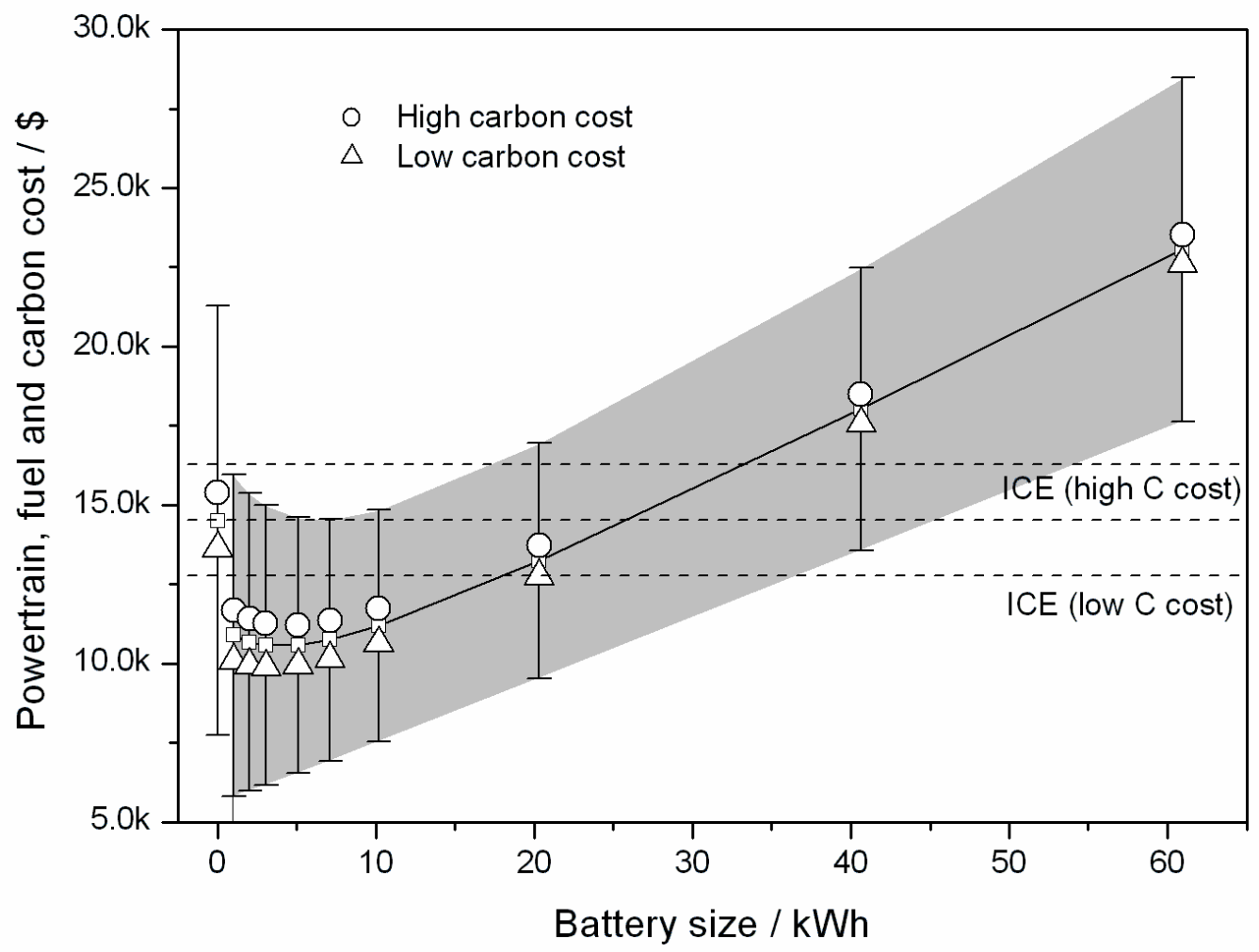

Figure 11. Sensitivity to carbon cost with carbon cost assumptions set high $(O)$ and low $(\Delta)$. The baseline cost for a petrol ICE with low, average and high carbon cost assumptions are shown as dashed lines

\subsubsection{Different vehicle sizes}

The results shown in figure 12 are the revised battery sizes for the 4 different vehicle sizes described in the National Travel Survey as small, small/medium, medium and large. These are calculated from the energy consumption figures shown in Error! Reference source not found. and the aggregated distance by car type extracted from the National Travel Survey shown in figure 3. Figure 12 demonstrates that vehicle size and average driver behaviour of different vehicle sizes is a key parameter in the present study. It is clear that the same battery size will not enable the same percentage of miles to be driven on electrical power for different vehicle sizes, because of both higher energy consumption and different driver behaviour. Consider the assumption that was made previously (Offer, Howey et al. 2010) that a $6 \mathrm{kWh}$ battery pack would enable the vehicle to operate on electrical power for $50 \%$ of the time. For the medium vehicle size based upon today's driving patterns this is true. However it is incorrect for the other sizes, where with today's driving patterns and a $6 \mathrm{kWh}$ battery pack the small, small/medium, and large vehicles would be capable of operating on electrical power for $68 \%, 58 \%$ and $32 \%$ of the time respectively. This is reflected in the results for the lifecycle costs of the different vehicle sizes (figure 13), where it can be seen that lifecycle costs increase with vehicle size. However, the predicted optimum battery size does not appear to be affected dramatically, with a marginal increase from a range between 2-4 kWh for a small vehicle to 3-7 kWh for a large vehicle. In addition there is a large impact on the percentage of miles that can be driven on electrical power for the different vehicle types, for the small vehicle this would be $65 \%$ for a $4 \mathrm{kWh}$ battery pack, and for the large vehicle would be $32 \%$ for a $4 \mathrm{kWh}$ battery pack.

The average $\mathrm{CO}_{2}$ emissions per kilometre for the different vehicle sizes are shown in figure 14 , and it can be seen that although the different energy consumption rates have the largest impact on the $\mathrm{CO}_{2}$ emissions, the effect of driver behaviour does have a negative impact on the 
larger vehicles where the lowest cost option corresponds to decreasing percentages of miles that can be driven on electrical power. However, as explained above it was assumed that there will be higher $\mathrm{CO}_{2}$ emissions per $\mathrm{km}$ for operating on the hydrogen fuel cell than operating on electrical power, and changes to these assumptions will affect the emissions, albeit not the percentage of miles that can be driven on electrical power.

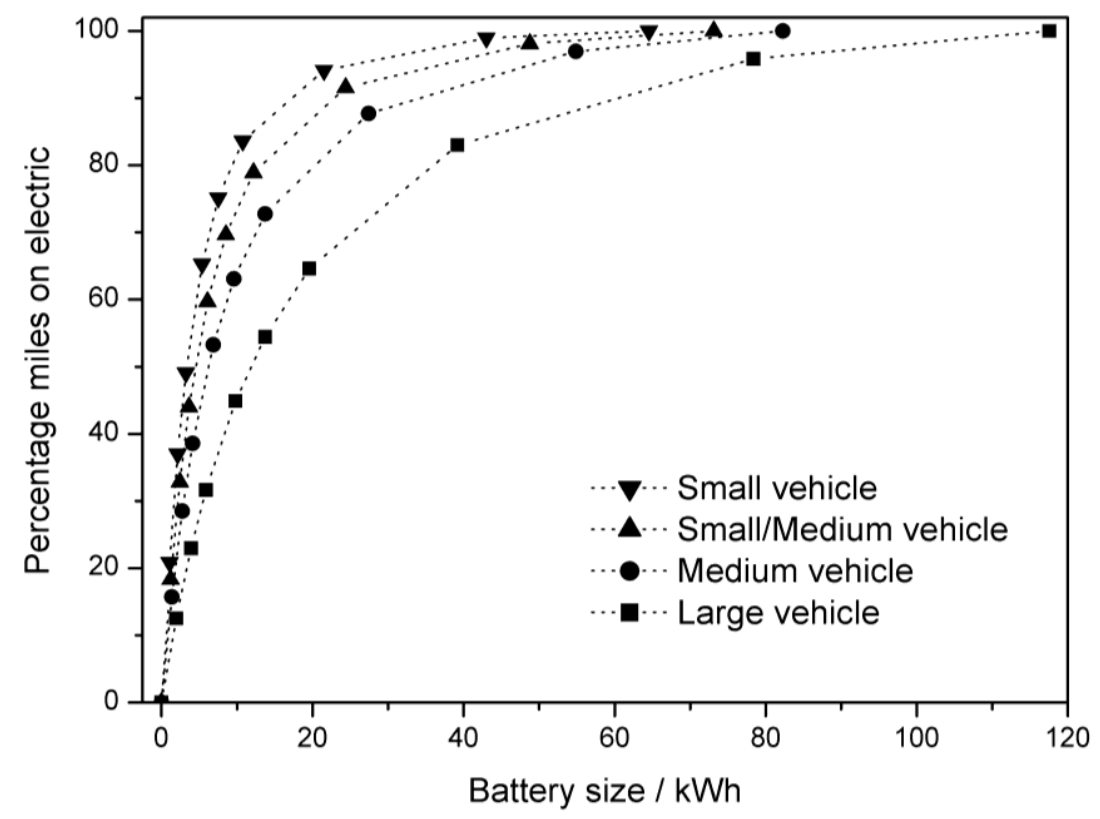

Figure 12. Revised battery size data for the 4 different vehicle types

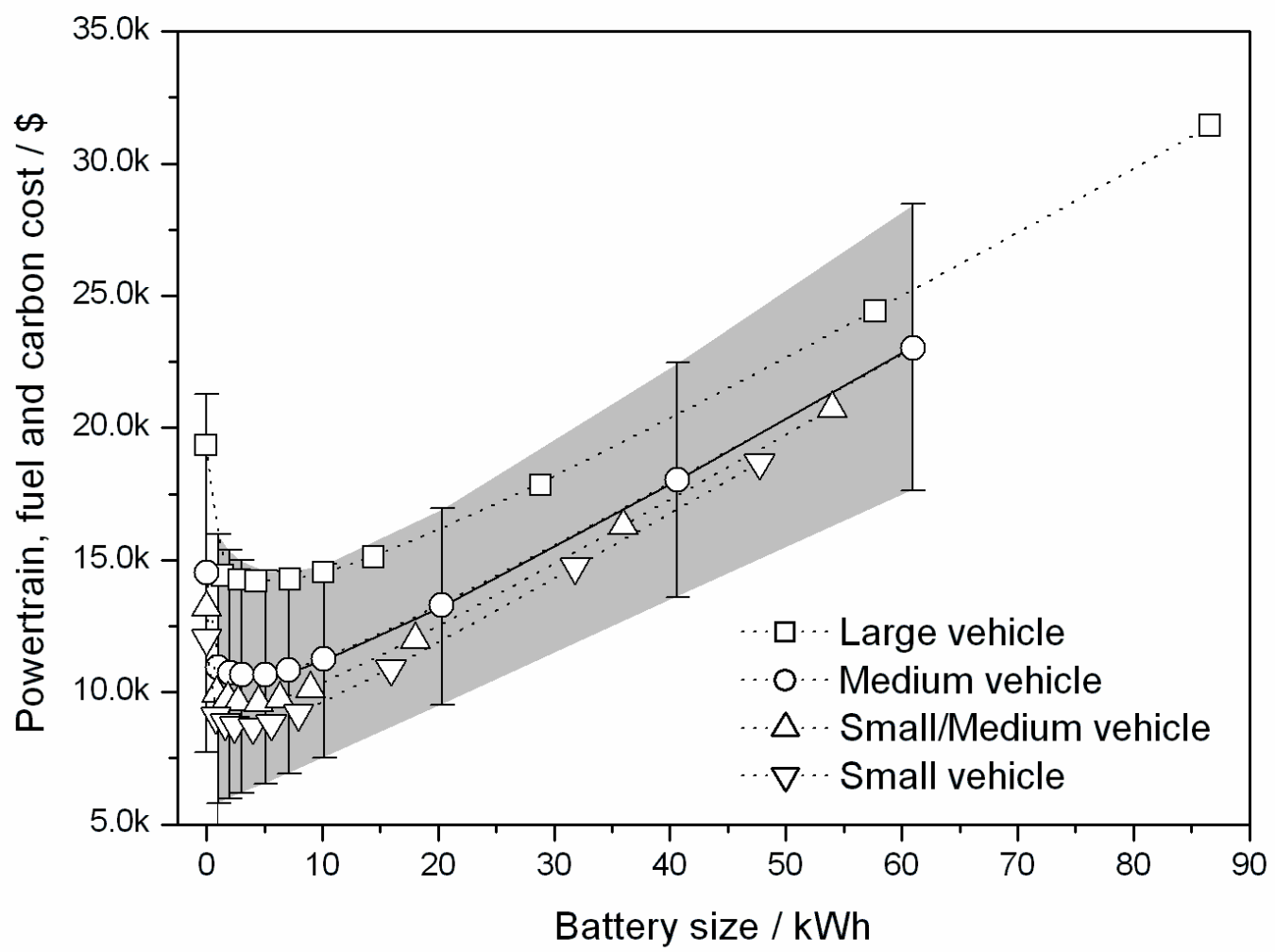

Figure 13. Sensitivity to vehicle type including behavioural differences and changes to powertrain and energy consumption assumptions shown in Table 6 and Figure 12. Error bars are shown for the medium vehicle. 


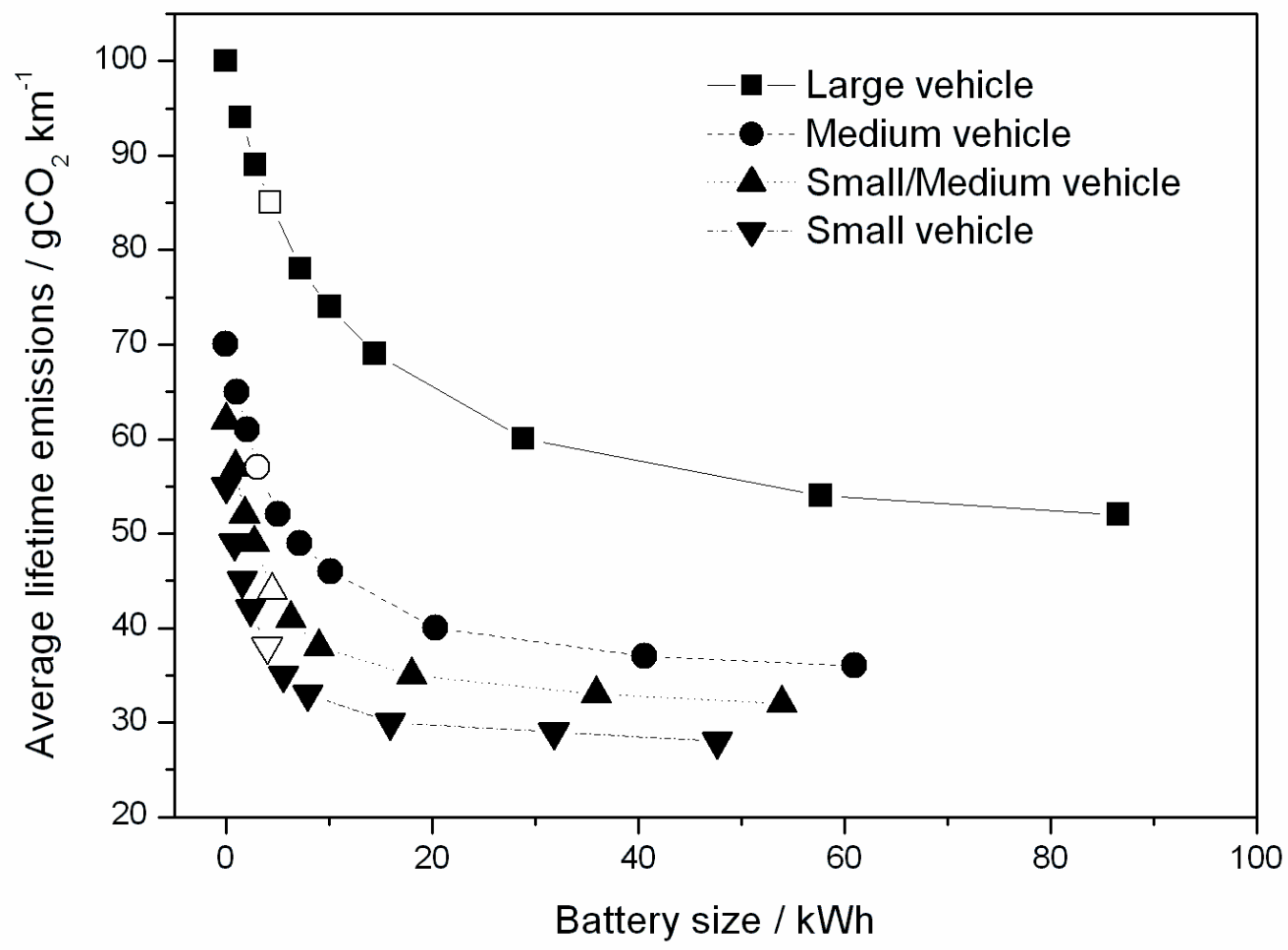

Figure 14. The $\mathrm{CO}_{2}$ emissions for the different vehicle types shown in figure 13, large (ם), medium $(\bullet)$, small/medium $(\boldsymbol{\Delta})$ and small $(\boldsymbol{\nabla})$, with the lowest cost option from figure 13 shown as hollow symbols

\section{Conclusions}

This paper has extended previous work (Offer, Howey et al. 2010) reviewing hydrogen fuel cell and battery electric vehicle options for a future sustainable road transport system in the UK. Behavioural aspects of vehicle use have been included, with an analysis of data on distance travelled by private car users daily extracted from the UK National Travel Survey (NTS) between 2002-2006 (Department for Transport 2008). A number of interesting conclusions can be drawn from the behavioural analysis:

- $\quad$ There is a significant law of diminishing returns for plug-in hybrid electric vehicles (HEV) with battery sizes above about 10-20 kWh, and with respect to cost, based on the assumptions in this paper, the optimum battery size for a FCHEV is likely to be between 5-15 kWh depending upon vehicle size and behavioural usage patterns.

- $\quad$ The size of vehicle is an important parameter, as larger vehicles tend to be driven further each day than smaller vehicles. This decreases the percentage of miles that can be driven using electricity in a larger vehicle with an equivalent electric only range compared to a small vehicle. This also decreases the cost savings per kWh battery and increases carbon emissions as a result of increased use of the range extender.

A number of interesting conclusions can be drawn from the combined behavioural and techno-economic analysis:

- The conclusion of our previous paper (Offer, Howey et al. 2010) that in terms of lifecycle costs the FCHEV is a cheaper option than conventional ICE vehicles in 2030, is reinforced. However, this is a function of the size of battery pack.

- If carbon is priced aggressively, then both the FCV and FCHEV become progressively cheaper than the conventional ICE vehicle, suggesting that higher carbon dioxide costs will increase the uptake of alternatively fuelled vehicles and contribute to lower emissions. 
- $\quad$ Battery costs are not critical when comparing the FCHEV against the FCV. Even for 'high' battery costs of $\$ 300 \mathrm{kWh}^{-1}$ the FCHEV is considerably cheaper than the FCV mostly because of the savings from downsizing the fuel cell. The lowest cost FCHEV has a predicted optimum battery size of between 5-15 kWh independent of battery cost. For larger battery sizes the costs become considerably larger, clearly demonstrating the law of diminishing returns for battery sizes bigger than $20 \mathrm{kWh}$. This suggests that a BEV without a range extender may certainly be more expensive than the FCHEV in 2030.

- $\quad$ Fuel cell costs have a large impact on the FCV costs but only a marginal impact on the FCHEV costs, and do not affect the predicted optimum battery size, which remains between 5-15 kWh.

- Decarbonising electricity generation unsurprisingly has a large impact on the lifecycle emissions of the FCHEV, but has a relatively small impact on the lifecycle costs. Decreasing carbon dioxide emissions from electricity generation by $80 \%$ significantly reduces the emissions of the FCHEV with battery sizes above approximately $10 \mathrm{kWh}$ reflecting the fact that, with increasing battery size, a significant percentage of journeys will be undertaken using electricity. However, no further reductions are achieved above 10-20 kWh because of the law of diminishing returns for increasing battery size. In addition the effect of the extra weight of additional batteries although not investigated here is likely to be non-negligible. Decreasing carbon dioxide emissions from electricity generation from $20 \%$ to $80 \%$ does not shift the optimum battery size for the FCHEV appreciably, but reduces the average emissions from 85-90 $\mathrm{gCO}_{2} \mathrm{~km}^{-1}$ to $40-50 \mathrm{gCO}_{2} \mathrm{~km}^{-1}$. However, no improvements in the carbon dioxide emissions from hydrogen production in 2030 were assumed, which may be a somewhat conservative assumption if new hydrogen production methods are developed.

- Hydrogen costs have a large impact on FCHEVs with a small battery size $(<10 \mathrm{kWh})$, and high hydrogen costs favour larger batteries $(>10 \mathrm{kWh})$, and low hydrogen costs favour smaller battery sizes $(<5 \mathrm{kWh})$.

- Vehicle size makes a considerable difference to the overall cost, larger vehicles being more costly. However, the FCHEV is considerably cheaper than the FCV for all vehicle sizes, and the optimum battery size is broadly independent of vehicle size, although with some variation. However, the percentage of miles that can be driven on electricity for the largest vehicles with the lowest lifecycle cost is considerably less than the other three vehicle sizes. This results in even higher $\mathrm{CO}_{2}$ emissions than would be expected by a comparison of vehicle size and weight alone and is a reflection of the larger percentage of long journeys undertaken in larger vehicles.

Some recommendations can therefore be made based on this study:

1. Hydrogen fuel cell electric vehicles could have a part to play in future road transport, but from a lifetime cost perspective the best platform for integration of fuel cells is the battery electric vehicle with fuel cell range extender. This platform also has the benefit of building on a technology roadmap that begins now with plug-in ICE hybrids.

2. Capital cost reduction of BEVs, FCVs and FCHEVs and their subcomponents should be a key target for ongoing development.

3. However, different rates of capital cost reduction of the key technologies are unlikely to change the conclusion that the FCHEV will be lower in cost than both the BEV and FCV, but they will change the optimum battery size, percentage of miles driven using electricity and associated $\mathrm{CO}_{2}$ emissions.

4. A single overnight charge using a domestic power supply would be sufficient to enable a plugin hybrid electric vehicle to be driven more than $80 \%$ of total miles driven using electricity. This is likely to require the least effort in upgrading of the electricity network compared to other scenarios, notwithstanding the additional electricity generation required, and would still offer opportunities to use such PHEVs as dispatchable loads if smart metering is in place.

5. A fleet of FCHEVs with an optimum battery size of roughly $10 \mathrm{kWh}$ would therefore require roughly two thirds of transport energy to be provided as electricity ( $~ 80 \%$ of miles driven) and one third as hydrogen ( $20 \%$ of miles driven). 
In summary, for policy-making purposes, it is suggested that battery electric and hydrogen fuel cell vehicles should not be regarded as antagonistic, either/or options but that both should be pursued and supported together. Analysis that does not account for behavioural and market aspects leads to results that are removed from the context, and therefore do not provide the right information to policy makers. In particular, it is quite clear that, even ignoring the issue of range, the economics of plug-in vehicles in general favour hybrid solutions, except in the (perhaps rare) case of small cars used mainly in urban areas and with very inexpensive batteries. The analysis present here therefore suggests that in a future decarbonised road transport system there is need for both batteries and fuel cells, with different degrees of hybridisation depending on the car type/size considered.

\section{Acknowledgments}

The authors gratefully acknowledge the financial support of the European Commission via the project HyTRAN for part of this work (EC Contract no.502577). 
This is a pre-print version of: Offer, G.J., et al., Techno-economic and behavioural analysis of battery electric, hydrogen fuel cell and hybrid vehicles in a future sustainable road transport system in the UK. Energy Policy (2011), doi:10.1016/j.enpol.2011.01.006

\section{References}

(2004). Passenger Cars: CO2 Emissions and Vehicle Excise Duty, Energy Saving Trust and Institute for European and Environmental Policy.

(2007). The ninth sustainability report, Society Motor Manufacturers and Traders (SMMT).

(2008). Transport Statistics Great Britain 2008, UK Department for Transport.

Anderson, T., Christophersen, O., Pickering, K., Southwood, H., Tipping, S. (2009). National Travel Survey 2008 Technical Report. Department for Transport, National Centre for Social Research.

Bandivadekar, A., K. Bodek, et al. (2008). On the Road in 2035 Reducing Transportation's Petroleum Consumption and GHG Emissions, Massachusetts Institute of Technology.

Bandivadekar, A., L. Cheah, et al. (2008). "Reducing the fuel use and greenhouse gas emissions of the US vehicle fleet." Energy Policy 36(7): 2754-2760.

Bradley, T. H. and C. W. Quinn (2010). "Analysis of plug-in hybrid electric vehicle utility factors." Journal of Power Sources 195(16): 5399-5408.

Burke, A. F. (2007). "Batteries and ultracapacitors for electric, hybrid, and fuel cell vehicles." Proceedings of the leee 95(4): 806-820.

CCC (2008). Committee on Climate Change (CCC) Building a low-carbon economy - The UK's contribution to tackling climate change, The First Report of the Committee on Climate Change.

DECC (2009). Department for Energy and Climate Change (DECC) UK Low Carbon Transition Plan.

Department for Transport (2008). National Travel Survey, 2002-2006 [computer file]. 2nd Edition. Colchester, Essex: UK Data Archive.

DfT (2005). Focus on Personal Travel 2005 Edition. Department for Transport. London, TSO.

DfT (2008). National Travel Survey, 2002-2006 [computer file]. 2nd Edition. Department for Transport Colchester, Essex: UK, Data Archive [distributor], August 2008. SN: 5340.

DfT (2009). Transport Statistics Bulletin National Travel Survey: 2008. Department for Transport. London, TSO.

DfT, B. (2008). Investigation into the Scope for the Transport Sector to Switch to Electric Vehicles and Plug-in Hybrid Vehicles. D. f. B. E. a. R. Reform and D. f. Transport.

European Commission (2006). Communication from the Commission to the Council and the European Parliament. Keep Europe moving - Sustainable mobility for our continent. Midterm review of the European Commission's 2001 Transport White Paper. Brussels, 22.06.2006. EC COM(2006) 314 final.

Eurostat (date of extraction: October 2008). "Electricity - domestic consumers - half-yearly prices." 
Granovskii, M., I. Dincer, et al. (2006). "Economic and environmental comparison of conventional, hybrid, electric and hydrogen fuel cell vehicles." Journal of Power Sources 159(2): 11861193.

Gross, R., P. Heptonstall, J. Anable, P. Greenacre, E4tech (2009). What policies are effective at reducing carbon emissions from surface passenger transport? A review of interventions to encourage behavioural and technological change. UKERC Technology and Policy Assessment.

Haryanto, A., S. Fernando, et al. (2005). "Current status of hydrogen production techniques by steam reforming of ethanol: A review." Energy \& Fuels 19(5): 2098-2106.

Heptonstall, P. (2007). A review of electricity unit cost estimates.

IEA (2004). IEA Technology Briefs: Energy Technologies for a Sustainable Future: Transport, International Energy Agency.

IEA (2007). IEA Energy Technology Essentials: Fuel Cells, International Energy Agency.

IEA (2007). IEA Energy Technology Essentials: Hydrogen Production and Distribution, International Energy Agency.

IEA (2008). IEA Renewable Energy Essentials: Wind, International Energy Agency.

IEA (2009). "Technology Roadmap Electric and plug-in hybrid electric vehicles."

King, J. (2007). The King Review of low-carbon cars. . H. Treasury. London, The Stationery Office. Part I: the potential for $\mathrm{CO} 2$ reduction.

King, J. (2008). The King Review of low-carbon cars. . H. Treasury. London, The Stationery Office. Part II: recommendations for actions.

Kromer, M. and J. Heywood (2008). "A Comparative Assessment of Electric Propulsion Systems in the 2030 US Light-Duty Vehicle Fleet." SAE Technical Papers.

McKinsey (2010). A portfolio of power-trains for Europe: a fact-based analysis. The role of Battery Electric Vehicles, Plug-in Hybrids and Fuel Cell Electric Vehicles.

Offer, G. J., D. Howey, et al. (2010). "Comparative analysis of battery electric, hydrogen fuel cell and hybrid vehicles in a future sustainable road transport system." Energy Policy 38: 24-29.

Suppes, G. J. (2005). "Plug-in hybrid with fuel cell battery charger." International Journal of Hydrogen Energy 30(2): 113-121.

Suppes, G. J. (2006). "Roles of plug-in hybrid electric vehicles in the transition to the hydrogen economy." International Journal of Hydrogen Energy 31(3): 353-360.

Tollefson, J. (2008). Car industry: Charging up the future. Nature News. 456: 236-440.

Van Mierlo, J. and G. Maggetto (2005). Fuel cell or battery: Electric cars are the future. Lucerne Fuel Cell Forum, Luzern, SWITZERLAND.

Yeh, S., D. H. Loughlin, et al. (2006). "An integrated assessment of the impacts of hydrogen economy on transportation, energy use, and air emissions." Proceedings of the leee 94(10): 1838-1851. 